Dr. Yasser Mymoon Abbass

Volume (2) No. (3) 2019

الاتجاهات الحديثة في النشـر العلمي للبحوث التربوية: أصول التربية نموذجاً

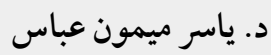




\section{الاتجاهات الحديثة في النشر العلمي للبحوث التربوية: أصول التربية نموذجاً}

$$
\text { د. ياسر ميمون عباس }
$$

$$
\text { أستاذ أصول التربية المساعد، كلية التربية النوعية - جامعة المنوفية، مصر }
$$

y_mymoon@yahoo.com

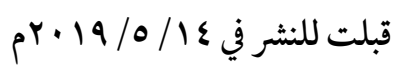

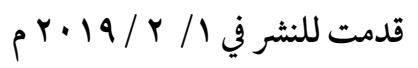

الملخص: يُمثل البحث العلمي أداة تقدم الأمم وعمادها، لذا يتوقف تقدم الدول على مدئ اهتمامها

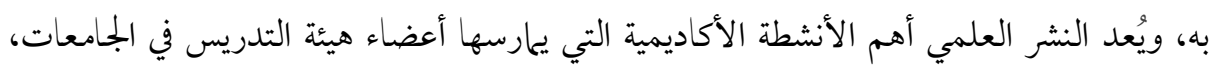
وتُقتيم الجامعات وتُصنف عالمياً في ضوء عدد البحوث التي تنشرها، وفن عصر الثورة التكنولوجية، والتوسع في استخدام الإنترنت، تطور النشر العلمي مستفيداً من الفرص التي تتيحها معطيات هذا العصر، وتناولت الورقة الحالية اتجاهات النشر العلمي الحديثة للاستفادة بها في مجال أصول التربية وذلك وفقاً لثلاثة محاور هي: المحور الأول وتناول النشر العلمي من حيث التعريف بمفهومه وأهميته وعرض لمراحل تطوره، مرحلة النشر الورقي، ثم مرحلة النشر المزدوج (ورقي وإلكتروني)، ثم مرحلة النشر الإلكتروني مع الشر الورقي حسب الطلب، ثم مرحلة النشر الإلكتروني الخالص. وتناول المحور الثاني واقع النشر العلمي لبحوث أصول التربية، من حيث معوقات النشر التي متردي تعترض الباحثين، المتعلقة بإجراءات النشر، والمتعلقة بالباحثين، والمتعلقة بالمجلات والدوريات العلمية، والمرتبطة بالجامعات، ثم محدودية أغلب موضوعات النشر، وأيضاً محدودية دور نشر الانتاج العلمي التربوي، وأخيراً الاعتهاد في النشر علن الأوعية المطبوعة أو الورقية. ثم المحور الثالث الأخير وتناول الاتجاهات الحديثة في النشر العلمي لبحوث أصول التربية وذلك من حيث قنوات النشر،

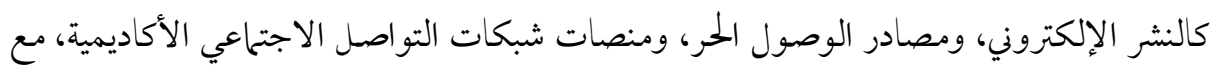
توضيح مميزات وعيوب كل منها، ثم الاتجاهات الحديثة من حيث موضوعات النشر، وأخيراً، الاتجاهات الحديثة من حيث تجويد النشر لبحوث أصول التربية ورفع كفاءة الباحثين، كالنشر الدولي، والنشر في مصادر لها معاملات تأثير وفق معايير عالمية، وإخضاع البحوث العلمية لبرامج فحص http://dx.doi.org/10.29009/ijres.2.3.7 


$$
\text { الانتحال، وإجراء البحوث الجلماعية أو بحث الفريق، وإشراك طلاب الجامعة في النشر العلمي. }
$$




\title{
Recent Trends in Scholarly Publishing for Educational Researches \\ "Foundations of Education as a Model"
}

\author{
Dr. Yasser Mymoon Abbass \\ Associate Professor of Foundations of Education, Faculty of Specific Education, \\ Menoufia University, Egypt \\ y_mymoon@yahoo.com
}

\section{Received 1st Feb 2019}

Accepted 14 May 2019

\begin{abstract}
The scientific publication is the most important academic activities practiced by faculty members in universities. The universities are evaluated and classified globally in light of the number of researches they publish, there has been an evolution of scientific publishing in the era of technological revolution and the expansion of the use of the Internet. Therefore, the present paper dealt with the trends of modern scientific publishing to be used in the field of the foundations of education, according to three axes: The first axis dealt with the scientific publishing concept, its importance and stages of development. The second axis dealt with the scientific publishing of the foundations of education researches, in terms of publishing obstacles facing researchers, in relation to publishing procedures, researchers, scientific journals, and universities. The third axis dealt with the latest trends in the scientific publishing of research on the foundations of education in terms of publishing channels, such as electronic publishing, open access resources, and academic networking platforms, and the latest trends in publishing topics. The impact factor of publication, the submission of scientific research to the programs of plagiarism, the conduct of collective research and the involvement of undergraduate students in scientific publishing.
\end{abstract}

Key words: E-publishing, open access, international publishing, academic platforms, plagiarism. 


\section{Summary:}

Scholarly Publishing is the most important academic activities practiced by faculty members in universities. This paper deals with the modern trends of scientific publishing to be used in the field of pedagogy, according to the following three axes:

The first axis: scientific publishing (concept, importance and stages of development):

Scholarly Publishing: A scientific process in which a summary of the researcher's work, knowledge and findings is presented to the development of society and solving its problems. The publication of scientific research is one of the most important mechanisms for sharing and enriching scientific knowledge and achieving the requirements of development. Scientific publishing has become one of the most important standards of Academic Ranking of World Universities. Scientific publishing is a prerequisite for academic and functional advancement. It is a guarantee of copyright. The stages of scientific publishing development are: paper publishing, then double publishing (paper and electronic), then electronic publishing with print on demand, and finally electronic publishing exclusively.

The second axis: The reality of the scientific publishing of the foundations of education research:

The reality of the scientific publication of research on the foundations of education has obstacles to researchers, where it is found that there are obstacles related to publishing procedures, researchers, journals and periodicals, and obstacles related to universities. And most of the publishing topics are limited.

The third axis: Recent trends in the scientific publishing of the research of the foundations of education:

\section{First: Recent trends in terms of publishing channels:}

There are several channels of scientific publishing that educational researchers in the field of pedagogy can use to publish their research, namely: 
1. Electronic publishing: which allows the availability of paper content in any form can be used by the computer such as storage media such as CDs or the Internet.

2. Open Access Resources: Open access resources provide free access to materials available online and to all users without restrictions or conditions. Because access to information hinders the progress of knowledge, researchers in the field of pedagogy can publish their intellectual production and make it available for free in various resources on the Internet, called open access resources. These resources include: Open Access Journals, both the profitability and the fee-based open access journals Or supported No-fee open access journals, self-archiving archives, and digital repositories.

3. Academic Social Networking Platforms:

The emergence of social networking platforms such as Google Scholar, LinkedIn, ResearchGate, and Academia.edu has fostered communication between researchers to share their scientific contributions and promote the movement of scientific publishing.

\section{Second: Recent trends in terms of publishing topics:}

Experts and researchers in the field of pedagogy sought to develop a research map for researchers in this field.

Third: Recent trends in terms of improving the publication of research on the foundations of education and raising the efficiency of researchers:

There are several trends to improve the publishing of research on the foundations of education, the most important of which is international publishing, publishing in sources that have impact factors according to international standards, 
subjecting scientific research to plagiarism programs, conducting group research or research, and engaging undergraduate students in scientific publishing.

\section{Conclusion:}

According to the above, it is possible to take advantage of the recent trends in the scientific publishing of educational research, especially in the field of pedagogy, through the following:

1. To provide researchers with the necessary competencies to benefit from the Internet and modern technologies in scientific publishing. This may be done through:

A. A - Holding training courses for faculty members and researchers in the field of pedagogy in order to provide them with the necessary competencies to benefit from the Internet and modern technologies in scientific publishing

B. B - Organizing workshops for faculty members so that they can benefit from those with experience in the fields of modern scientific publishing.

2. Encouraging researchers to publish online on the Internet, and can be achieved by:

A. A - Holding seminars on the electronic publication and its advantages and disadvantages and how to benefit researchers from the advantages and avoid defects.

B. B- Holding conferences to discuss the use of the available resources on the Internet to serve scientific publishing.

3. Raising awareness of international publishing problems such as phantom or pseudo-patrols.

4. Develop the skills of researchers to cope with scientific plagiarism, and can be done by: 
A. Holding training courses for academics and researchers in the skills of scientific research and scientific writing.

B. Holding workshops for academics through which good practices of good researchers are identified.

5. Encourage researchers to publish in sources that have impact factors according to international standards. This can be done by:

A. Allocation of publishing bonuses to faculty members who publish their research in sources with high impact factors. 
يتوقف تقدم الدول علئ مدى اهتمامها بالبحث العلمي، واعتمادها علن نتائج البحوث العلمية المنشورة في شتى ميادين التنمية، فلا قيمة للبحوث غير المنشورة، حيث إن النشر العلمي يتضمن خضوع هذه البحوث لعملية التحكيم، كما أنه يبين مدئ قيمتها العلمية ورصانتها. ويُعد النشر العلمي أهم الأنشطة الأكاديمية التي يمارسها أعضاء هيئة التدريس في الجامعات، بل وصل الأمر في عديد من الأوساط الأكاديمية في دول العالم إلى اعتبار النشر العلمي أحد أهم المحكات التي قد يتوقف عليها الإبقاء علن الأكاديميين في وظائفهم، أو الاستغناء عنهم؛ لتظهر عبارة مشهورة في الجامعات المتقدمة مضمونها "النشر أو الهلاك" (Publish or Perish) (مصطفى، 7 أب Y، TVT ) و هي مقولة تم صياغتها لوصف الضغط الواقع على أعضاء هيئة التدريس في الجامعات والمؤسسات البحثية لنشر العمل الأكاديمي بسرعة وبشكل مستمر للحفاظ علن مو اقعهم الأكاديمية أو الترقي فيها. وفن عصر الثورة التكنولوجية، والتوسع في استخدام الإنترنت، الذئ ألقى بظلاله على المناشط الأكاديمية فطبعها بطابعه، فتحولت المكتبات إلى مكتبات إلكترونية متغلبة بذلك على الحيز المكاني والزماني، حتى المؤتمرات واللقاءات العلمية أمكن إجراؤها باستخدام الإنترنت فظهر ما يطلق عليه بالإنجليزية webinars أي حلقات البحث عن طريق الانترنت في مقابل seminars أي السيمنارات العلمية التقليدية (McNally, 2017, 50)، وتطورت الكفايات اللازم توافرها لدني الباحث في العلوم الاجتحاعية لتشمل في مرحلة ما قبل إعداد البحث، مهارات التعامل مع المكتبات الرقمية، وقواعد البيانات ومحركات البحث في الإنترنت؛ والكفايات اللازمة أثناء إعداد البحث؛ لتحكيم أدوات البحث وتطبيقها إلكترونياً؛ ثم كفايات مرحلة ما بعد إعداد البحث؛ لتشمل القدرة علن النشر الإلكتروني، والمشاركة في المؤتمرات وحلقات النقاش الإلكترونية (مصطفى، سا +r، هبr - • ع (1)، وفن ظل هذا العصر الرقمي تطور النشر العلمي أيضاً مستفيداً من الفرص التي تتيحها 
معطياته، وسوف تتناول الورقة الحالية اتجاهات النشر العلمي الحديثة للاستفادة منها في مجال أصول

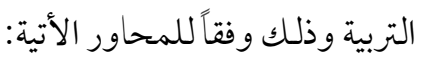

$$
\text { الأول: النشر العلمي (مفهومه وأهميته ومر احل تطوره). }
$$

الثالث: الاتجاهات الحديثة في النشر العلمي لبحوث أصول التربية.

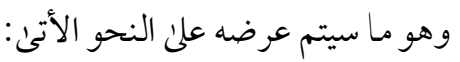

المحور الأول: النشر العلمي (مفهومه وأهميته ومر احل تطوره):

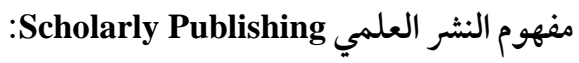

النشر لغة: هو الإذاعة أو الإعلان بين الناس، ففي مختار الصحاح، انتُشَّر الخبر ذاع (الرازئ،

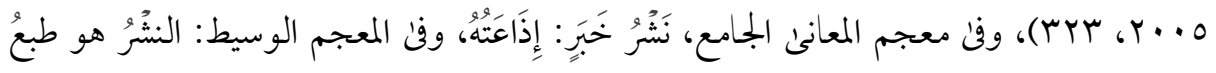

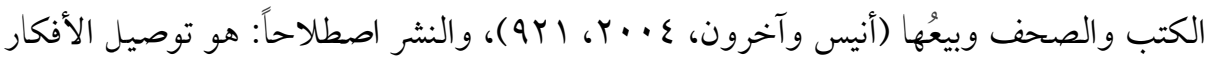

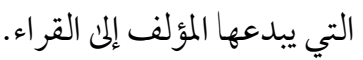

وفن ضوءما سبق يمكن القول إن الشر العلمي عملية يتم من خلالها تقديم خلاصة ما أنجزه

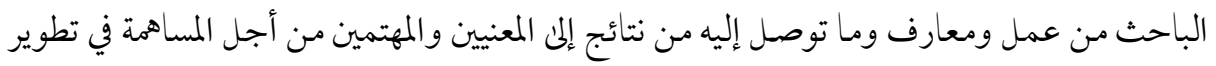

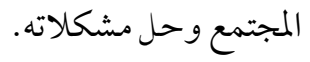

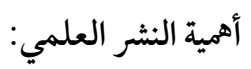

1. يتيح الفرصة أمام الباحثين للتعرف علن نظرائهم في جامعات العالر المختلفة، وما يترتب علن

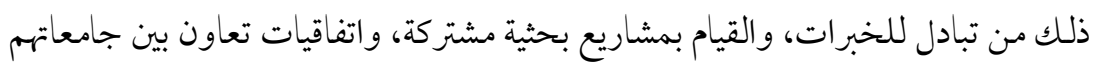

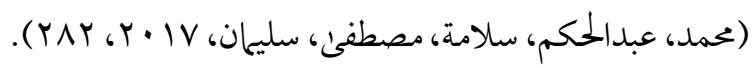
r. يعد نشر البحوث العلمية أحد أهم آليات مشاركة وإثراء المعرفة العلمية وتحقيق متطلبات http://dx.doi.org/10.29009/ijres.2.3.7 


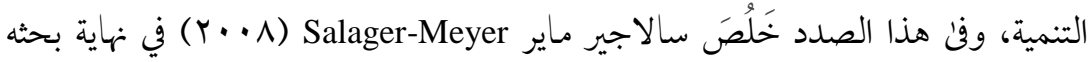
المعنون بـ "النشر العلمي في البلدان النامية: تحديات للمستقبل"، إلى أن العلم والتكنولو جيا و النشر يشكلون مثلث لا غنى عنه لبقاء الدول النامية (Salager-Meyer, 2008, 129). ب. أصبح النشر العلمي أحد أهم المحكات الرئيسة التي تُقيَّم الجامعات وتُصنَّف عالمياً في

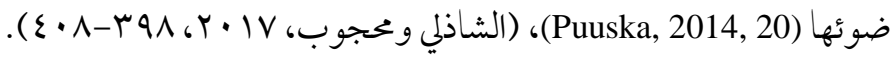
ع. يمثل النشر العلمي شرطاً أساسياً للترقية الأكاديمية والوظيفية، وهو الأمر الذئ تشير إليه دراسة باسكا Puuska, 2014, 20) Puusa)، وتؤكد عليه نتائج دراسة آدمز Adams (r) Academic Promotion عن المعايير الواجب اتباعها عند الترقية الأكاديمية) حيث جاء في المرتبة الأولى من هذه المعايير نشر عضو هيئة التدريس لكتاب أضاف للمعرفة في مجال تخصصه، كما جاء نشره لمقالات أو تقارير محكمة في المرتبة الثانية في قائمة هذه المعايير (Adams, 2003, 244-246)، مما يؤكد علنى أهمية النشر العلمي كمعيار يؤخذ به عند ترقية الأكاديميين.

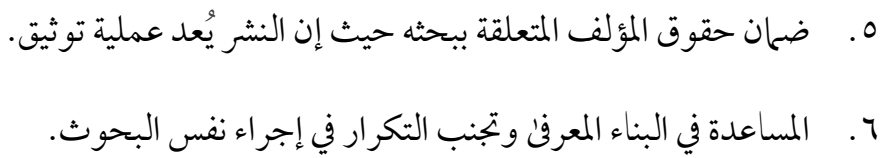
وقبل كل ذلك فإن نشر العلم ليستفيد منه الآخرين سبباً في تحصيل المثوبة من الله عز وجل والبعد عن العقوبة في الآخرة، فعن أبي هريرة رضي الله عنه أن رسول الله قال: "إِذَا مَاتَ ابْنُ آدَمَ

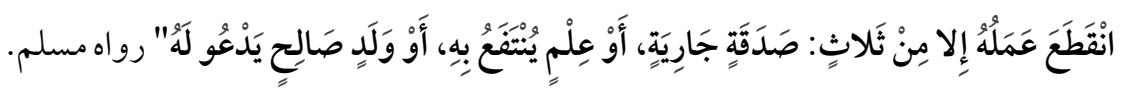
مراحل تطور النشر العلمي: - مري:

قد تتعدد صور المحتوئ العلمي المنشور فقد يكون ورقة بحثية Research paper أو ورقة

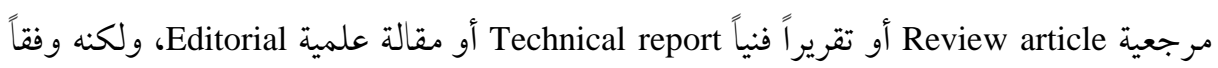
لمحمد وآخرون (Y V (Y) يُصنف من حيث صناعته إلى النشر التقليدي والنشر المكتبي والنشر 
الإلكتروني، ومن حيث الهدف منه إلى النشر التجاري، والنشر غير التجاري (محمد، عبد الحكم،

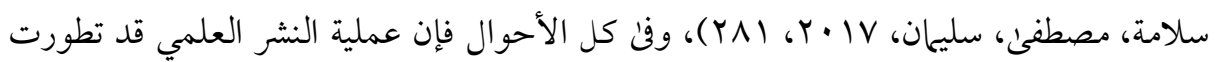
وفقاً لعدة مر احل يمكن عرضها فيما يأتي:

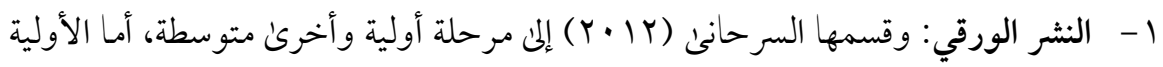
فتتمثل في مرحلة الأصول الورقية كالكتب بمختلف أنواعها، والدوريات والتقارير

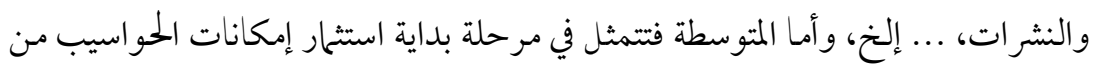
حيث التحرير والطباعة ومن ثم إخراج المعلومات بشكل ورقي متميز عن الشكل السابق،

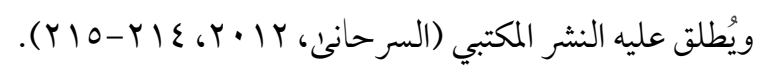

r- النشر المزدوج (ورقي وإلكتروني): في هذه المرحلة يتم إنتاج وتوزيع المطبوع في شكلين متوازيين أحدهما مقروء بالآلة، والثاني مطبوع علن الورق ولكل نوع ميزات يمتاز بها عن هن

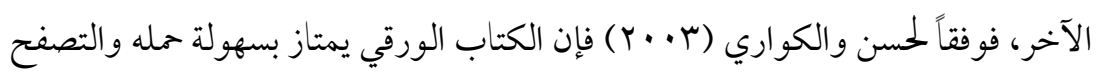
بين محتوياته والتأشير عليه، والاطلاع علن أكثر من كتاب في وقت واحد، وتجنب أضرار الجلوس أمام الحاسوب، في حين يمتاز الكتاب الإلكتروني برخص ثمنه وسهولة الاقتباس المباشر منه خاصة عند التعامل مع الموسوعات العلمية متعددة المجلدات والتي تحتل حيزاً كبيراً في المكتبات في حين يمكن الاستعاضة عنها باسطوانة مدبجة تحمل هذه الموسوعات المهات وسهلة التصفح، وعلن الرغم من أن النشر الإلكتروني قد غير من سلوكيات البحث عن المعلومات وتخزينها واسترجاعها وتصنيفها إلا أن ذلك لم يحد من استخدام الكتاب الورقي لأن الريادة في نقل المعرفة والتعريف بالثقافات الأخرى مازالت للكتاب الورقي (حسن

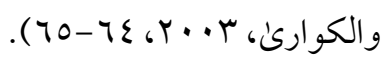

ץ- النشر الإلكتروني مع النشر الورقي حسب الطلب (Print on Demand): وفيه يكون التسويق أو المتاجرة الإلكترونية أي البيع والشراء للمحتوىن سواء ورقي أو إلكتروني من

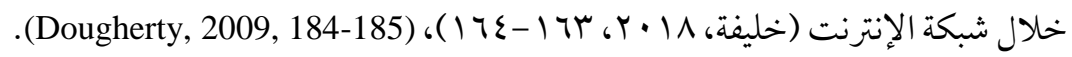


ع - النشر الإلكتروني الخالص: يكون مصدر المعلومات وفقاً للهوش (1 +. ب) غير ورقي منذ البداية، وأن كل مؤلف يقوم بإدخال البيانات الخاصة بكتابه من خلال حاسوبه وفق برجيات خاصة، وفى هذه المرحلة يكون باستطاعة الفرد التجول بحرية ضمن المصادر المتاحة له عبر شبكات المعلومات التي تربط بين المؤلفين والناشرين والمستفيدين (الهوش،

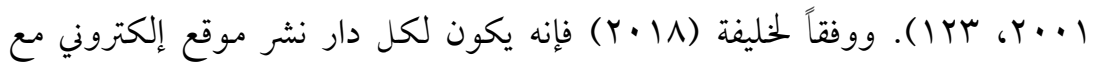
استخدام البريد الإلكتروني للتواصل كبديل للوسائل التقليدية الأخرىن كالفاكس، ويكون تسويق المحتون الإلكتروني من خلال وسيلتين الأولن: إنشاء موقع لنشر المحتون الإلكتروني مجاناً والاعتماد على الدخل الذئ يدخل للموقع مقابل الإعلانات التي تضعها شركات الإعلان المتخصصة عبر هذا الموقع، والثانية: إنشاء أو الاشتراك في مواقع البيع المباشر للمحتوى الإلكتروني عن طريق التنزيل أو الاشتراكات الشهرية أو السنوية بنظام الدفع عن طريق البطاقات الائتحانية في مقابل الاطلاع والبحث المفتوح، ومن الممكن دمج الإمكانيتين في موقع واحد، ومن أمثلة هذه المواقع موقع أمازون (www.amazon.com)

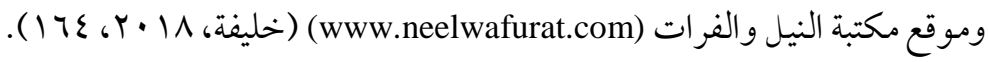
المحور الثاني: واقع النشر العلمي لبحوث أصول التربية: يمكن تبين واقع النشر العلمي لبحوث أصول التربية من خلال النقاط الآتية: ا ـ معوقات النشر التي تعترض الباحثين: وفقاً لنتائج بحث الشربيني ومحمد (ع ا ب) الذئ استهدف التعرف علن معوقات النشر العلمي في العلوم التربوية من وجهة نظر أعضاء هيئة التدريس بالجامعات السعودية، تبين أن هناك معوقات تتعلق بإجراءات النشر كانت أبرزها: الافتقار إلى قاعدة بيانات لكل ما ينشره الباحثون في الدوريات العربية، وغياب خريطة واضحة للنشر العلمي في الموضوعات المطلوبة، وتنعكس آثارها بشكل مباشر علن النشر العلمي، وقصور دور الهيئات الاستشارية للمجلات العلمية، ونقص الهيئات 
أو اللجان المتخصصة لتطوير نظام النشر العلمي، وقيام المحكمين بعمليات التحكيم للبحوث العلمية علن هامش عملهم، وكانت أبرز المعوقات المتعلقة بالباحثين هي: ضعف الحافز المادي و المعنوي للنشر العلمي، وكثرة الأعباء التدريسية والإدارية، وعدم وجود قنوات تو اصل بين الباحثين علن المستون المحلن والدولي، وصعوبة العضوية في بعض جهات البحث العلمي المحلية والعالمية، وصعوبة إجراءات النشر في المجلات العالمية، وكانت أبرز المعوقات المتعلقة بالمجلات والدوريات العلمية هي: طول فترة الانتظار للنشر في الدوريات المحكمة، وعدم اعتماد بعض المجلات العلمية المتاحة من قبل لجان الترقية، وتأخر صدور الأعداد الخاصة بالمجلات والدوريات عن موعدها، واهتحام بعض بره المجلات بالجانب المادي علن حساب جودة البحوث، وعدم وضوح معايير تصنيف المجلات والدوريات، أما المعوقات المرتبطة بالجامعات فكان أبرزها: ضعف تمويل البحث العلمي في بعض الجامعات، وتوجه البحث العلمي لغايات الترقية بشكل أساسي، وغياب التنسيق بين الجامعات مما يؤدئ إلى تكرار بعض البحوث، وعدم توفر البيئة البحثية المناسبة لأعضاء هيئة التدريس، وعدم ربط البحث العلمي بشكل كاف بالمؤسسات الإنتاجية، وعدم وجود آليات واضحة لتبادل النشر العلمي

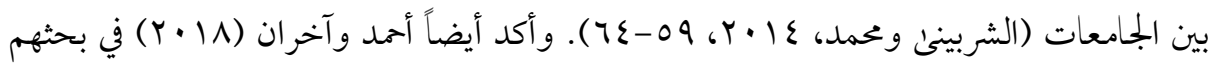
الذئ استهدف وضع تصور مقترح لتطوير مجال أصول التربية في ضوء بعض النماذج العالمية على وجودصعوبات تتعلق بعملية النشر العلمي للأبحاث التربوية ترجع في بعض الأحيان إلى الشروط والإجراءات المتبعة في نشر البحوث والدراسات في المجلات والدوريات العلمية، كما ترجع إلى زيادة النفقات والأعباء المادية، وما تتطلبه البحوث من إمكانيات تتجاوز في بعض الأحيان قدرات الباحثين

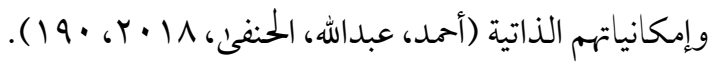

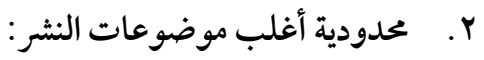

أظهرت نتائج بحث أجر اه مهنى غنايم (ع ( • ) للتعرف على واقع البحوث التربوية العربية المنشورة من خلال الاطلاع على بسا بحثأ موزعة على (ع7) بجلة عربية لنشر البحوث التربوية،

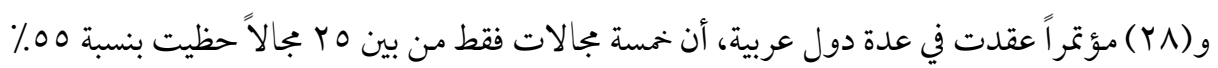


تقريباً من إجمالي البحوث حيث إن مجموع بحوث هذه المجالات الخمس بلغ (ع/ ا) بحثاً، وهذه

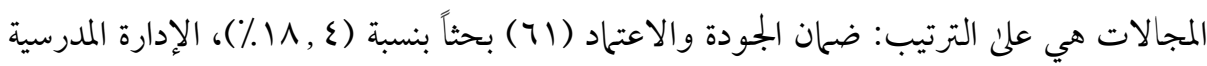
والإشراف التربوي (جr) بحثً بنسبة (11\%)، التطوير والإصلاح المدرسي (ع) بحثاً بنسبة

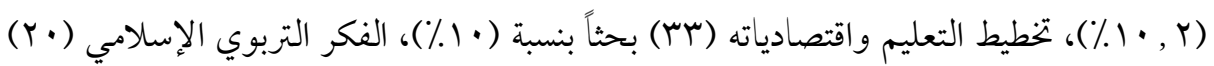

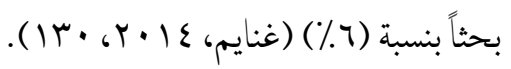

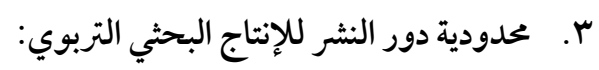
يوجد عدد محدود نسبياً من دور النشر التي تهتم بنشر الإنتاج العلمي التربوي، حيث يشير

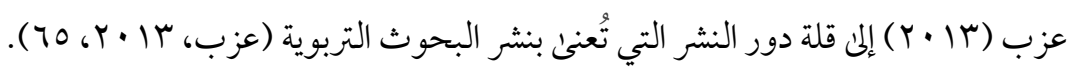
ع.الاعتحاد في النشر على الأوعية المطبوعة أو الورقية: يُعد النشر في الأوعية المطبوعة أو الورقية أكثر الوسائل التي يعتمد عليها العلماء لنشر نتائج أعمالهم الأكاديمية، إضافة إلى ما كانت تمثله تلك المطبوعات من مصدر ربح للناشرين (مصطفى،

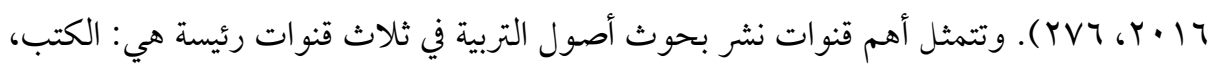

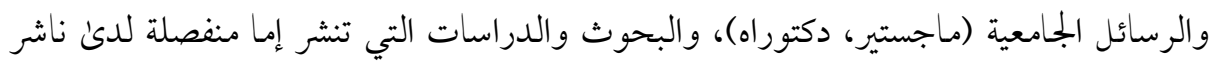

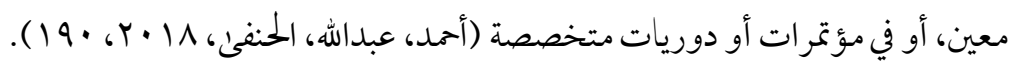
المحور الثالث: الاتجاهات الحديثة في النشر العلمي لبحوث أصول التربية: يمكن عرض الاتجاهات الحميثة في النشر العلمي التي يمكن الاستفادة منها في نشر بحوث أصول التربية وفقاً لثلاثة محاور هي: 1 - - الاتجات الحديثة من حيث قنوات النشر.

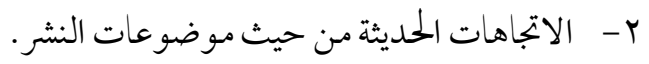
r- الاتجاهات الحديثة من حيث تجويد النشر لبحوث أصول التربية ورفع كفاءة الباحثين. 
وفيا يأتي عرض لهذه المحاور:

\section{أو لاً: الاتجاهات الحديثة من حيث قنوات النثر:}

هناك عدة قنوات للنشر العلمي يمكن للباحثين التربويين في مجال أصول التربية الاستعانة بها

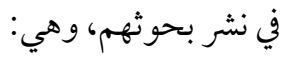

1. - النشر الإلكتروني:

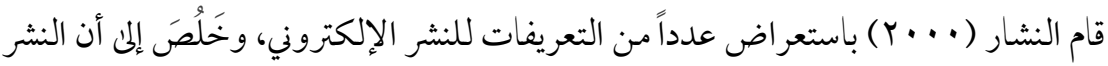

الإلكتروني هو ذلك النوع من النشر الذئ يستخدم التكنولوجيا وبخاصة الحاسب الآلي في كافة عمليات إنتاج الرسالة الفكرية وهي التأليف وتجهيز خطوطة المؤلف، والتوزيع والتداول خلال وسيط إلكتروني كالممغنطات والمليزرات، فجوهر التعريف عنده هو استخدام التكنولوجيا لإنتاج وسيط إلكتروني سو اء كان ذلك عن طريق نظم مستقلة كالحاسبات الشخصية أو عن طريق الشبكات علن اختلاف مستوياتها، وسواء كان المنشور الإلكتروني ناتجاً عن التحويل من الشكل المطبوع إلى

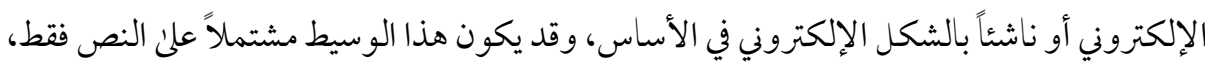

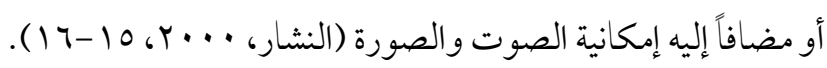

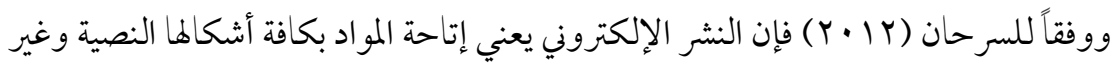
النصية في شكل إلكتروني عبر وسيط مليزر أو ممغنط أو عن طريق بثه عبر إحدى الشبكات بحيث

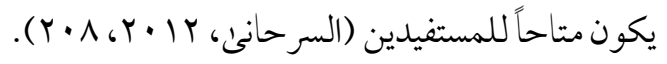

ووفقاً لخليفة (1) (Y) فإن الشر الإلكتروني هو استخدام كافة إمكانات الكمبيوتر من الأجهزة وملحقاتها والبربجيات في تحويل المحتوى المنشور بطريقة تقليدية كالكتب والدوريات الورقية إلى محتوئ منشور بطريقة إلكترونية علن أسطوانات ليزر أو من خلال الإنترنت (خليفة، 
وبالنظر للتعريفات السابقة يتبين أنها تتفق علن أن النشر الإلكتروني يتسم بإتاحة المحتون الورقي في أي شكل يُمكن استخدامه بواسطة الحاسب الآلي مثل وسائط تخزين المعلومات كالأسطو انات أو عبر الإنترنت.

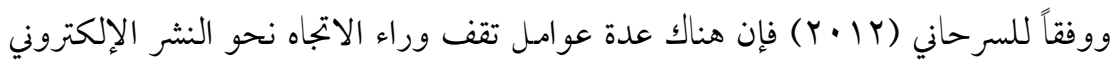
بدلاً من النشر الورقي، مثل: قلة التكاليف، وتوفير الوقت المستغرق للنشر، والحفاظ علن موارد البيئة من الأشجار اللازمة لصناعة الورق، وكذلك الحدد من المخلفات الورقية، والاقتصاد في الحيز المكاني لاقتناء مصادر المعلومات والحفاظ عليها، والتخلص من مشاكل النقل والشحن وأيضاً التنظيم والتصنيف والفهرسة للمصادر الورقية، هذا فضلا عن الاستفادة من الفرص التي تتيحها الحواسيب

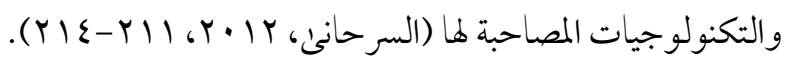

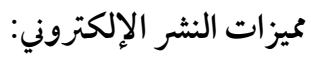

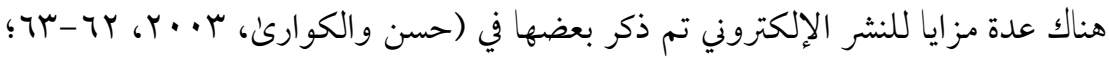

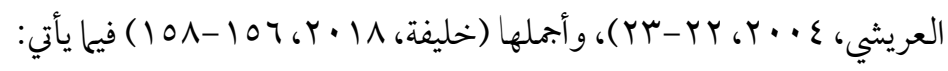

ا - قلة التكاليف الخاصة بالنشر لعدم الحاجة إلى الطباعة والتجليد والتغليف، وكذا التكاليف الخاصة بالتخزين والشحن.

r- عدم الحاجة لموزعين حيث تكون العلاقة بين الناشر والمستخدم النهائي مباشرة. بـ- الانتشار فإتاحة المحتوى الإلكتروني علن الإنترنت يتيح الحصول عليه في أي مكان في العاله. ع - طرق التسويق المبتكرة حيث يتم الاستفادة من محركات البحث وطرق التسويق الإلكتروني في الترويج والإشارة إلى موقع تواجد المحتوى الإلكتروني علن الإنترنت والناشر الذئ يقدمه. ه- الاستمرارية حيث إن الكتاب الإلكتروني لا تنفد طبعاته من السوق كما هو الحال في الكتاب

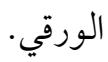

\section{http://dx.doi.org/10.29009/ijres.2.3.7}


7- سرعة إعداد الإصدارات الجديدة نتيجة لسهولة التعديل بالإضافة والحذف للمحتوكن

الإلكتروني.

V - المحافظة علئ البيئة من خلال الحدمن التلوث الناتج عن مخلفات صناعة الورق.

1- سهولة الاستخدام من حيث سهولة البحث داخل المحتوى الإلكتروني، ووجود إمكانية الطباعة لأجزاء بعينها من المحتوني، وإمكانية استخدام الوسائط المتعددة، وإمكانية التعرف علن معانئ الكلمات والمصطلحات من خلال الروابط بالقواميس والمعاجم، وسهولة الاستخدام في التعليم والتدريب، وتوفير الحيز المكاني للتخزين، والنشر الذاتي حيث يستطيع المؤلف النشر علن موقع خاص به دون الحاجة لدور نشر.

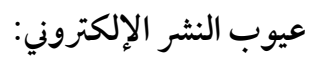

هناك عدة عيوب للنشر الإلكتروني، فلقد بين شاهين (11) عدداً من عيوب النشر الإلكتروني مثل: العبث في المعلومات الإلكترونية كتحريف المعلومات، والإتاحة السهلة لمعلومات ضارة قد ترتبط بالدين أو بالصحة أو بالظروف الاجتحاعية، وانتهاك معلومات التو اصل الاجتماعي والخصوصية، ونشر الفيروسات والاختراقات وتعطيل الأجهزة، وعدم وجود جهة تحكم وتضبط المحتوئ علن الشبكة، وغياب التشريعات العالمية لضبط تدفق المعلومات سوئ بعض القوانين الفردية

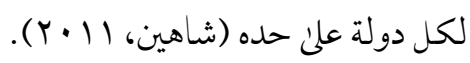

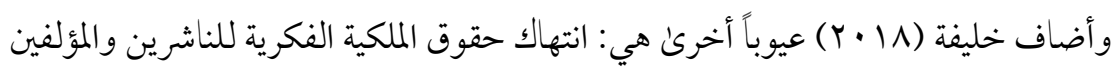
لسهولة نسخ ونشر المحتون الإلكتروني دون الرجوع للمؤلف، والحاجة لتوفر أجهزة خخصصة لاستخدام المحتوى الإلكتروني، وصعوبة القراءة من الشاشة للأجهزة الإلكترونية مقارنة بالكتاب الورقي، ومشكلات التسويق الإلكتروني للمحتون علن الإنترنت وبخاصة في الدول العربية من

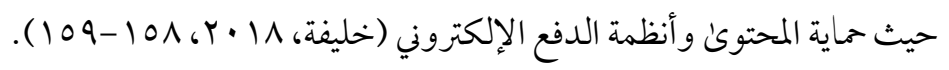




\section{معوقات النشر الإلكتروني بالنسبة للباحثين في أصول التربية:}

هناك بعض المعوقات التي قد تعترض الباحثين في بجال أصول التربية فيها يتعلق بالنشر

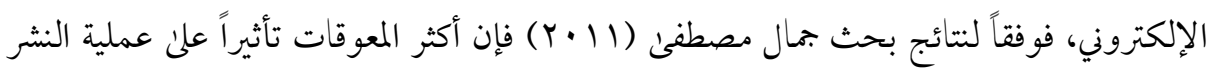
الإلكتروني الأكاديمي من وجهة نظر أعضاء هيئة التدريس والباحثين بالجامعات العربية في مصر و السعودية واليمن و الإمارات، كانت: قلق عضو هيئة التدريس حول قبول بحثه للترقية في حال كون النشر إلكترونيا، وقلة برامج التنمية المهنية لأعضاء هيئة التدريس والباحثين في بجال التقنيات المشجعة للنشر الإلكتروني؛ وقلة معرفة عضو هيئة التدريس بمواقع أو أوعية النشر الإلكترونية المعترف بها

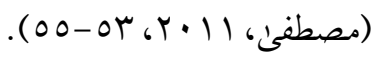

ووفقاً لنتائج بحث ملحم (10 · r ) عن معوقات النشر العلمي الإلكتروني من وجهة نظر أعضاء هيئة التدريس بجامعة نايف العربية للعلوم الأمنية، كانت أبرز المعوقات هي: النظرة العلمية غير الجادة للأبحاث المنشورة إلكترونياً، وخوف عضو هيئة التدريس من عدم اعتراف لجان الترقية بأبحاثه المنشورة إلكترونياً، وعدم الثقة بمعايير النشر الإلكتروني وخاصة التحكيم العلمي، وخوف أعضاء هيئة التدريس من سرقة أبحاثهم حال نشرها إلكترونياً (ملحم، 10 • Y، Y I I).

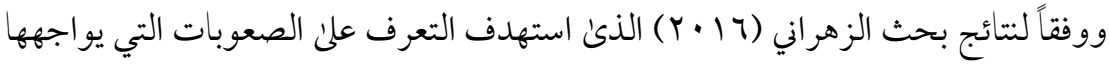
أعضاء هيئة التدريس بجامعة أم القرى عند محاولة نشر إنتاجهم الفكري إلكترونياً، تبين أن أهم العقبات التي تقف أمـام الباحثين تتمثل في حاجتهم إلى مزيد من التدريب وإتقان بعض المهارات التقنية للتعامل مع الأجهزة والمو اقع الإلكترونية دون الحاجة إلى وجود وسيط، وحاجتهم إلى مزيد من التوعية بجدون وأهمية النشر الإلكتروني، ووجود بعض المشكلات الفنية المتعلقة بالتقنية وشبكة المعلومات مثل بطء الإنترنت وتعرض الحواسيب للفيروسات أو الاختراق (الزهرانئ، 17 • ب، .$(14 q-142$

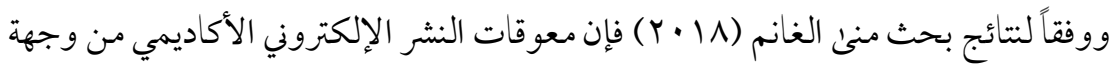


نظر أعضاء هيئة التدريس في جامعتي الإمام محمد بن سعود والملك سعود بالرياض، كانت: قلق

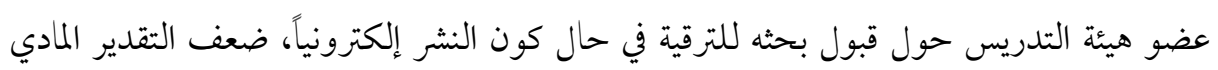

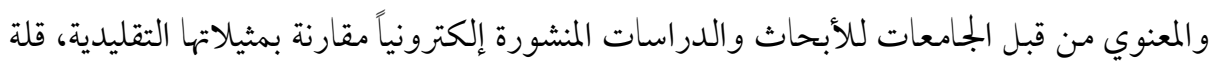
برامج التنمية المهنية لأعضاء هيئة التدريس والباحثين في بجال التقنيات المشجعة للنشر الإلكتروني،

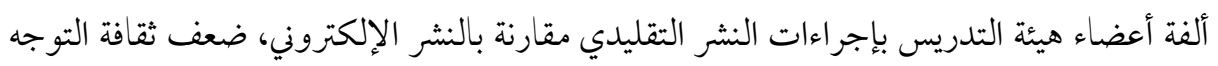

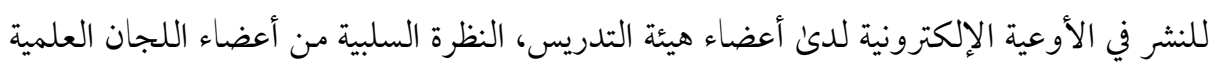

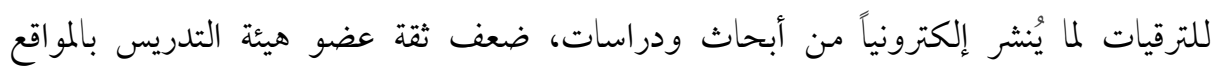

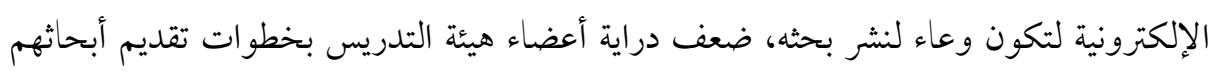

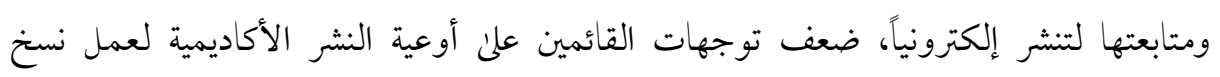

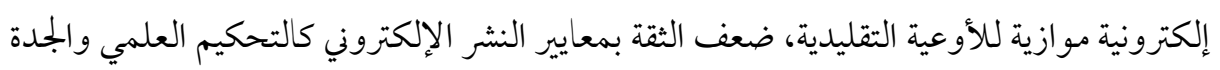

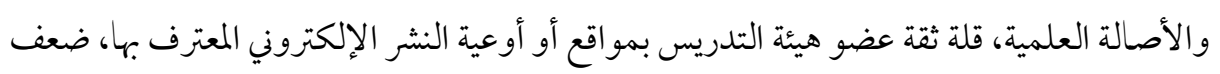

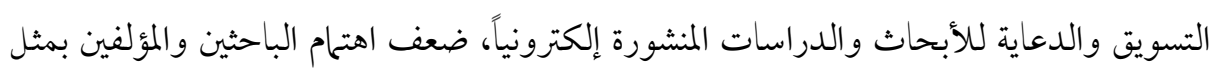

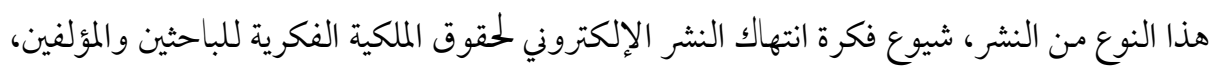

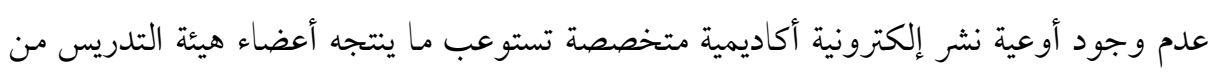

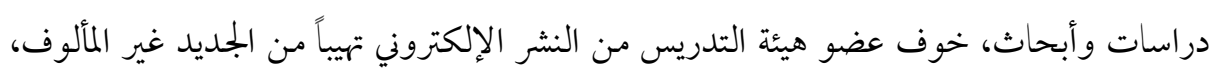

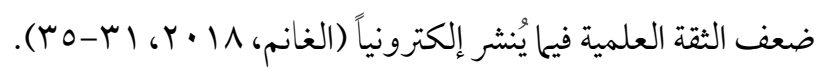

\section{r. مصادر الوصول الحر:}

يُقتصد بالوصول الحر للمعلومات إمكانية الوصول إلى المواد المتاحة عبر الإنترنت بجاناً

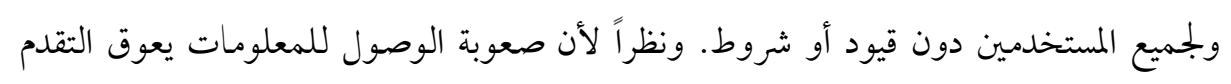

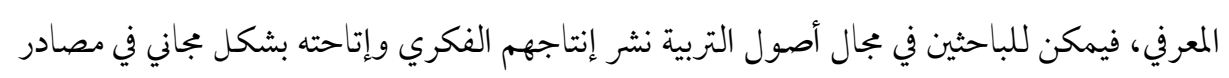

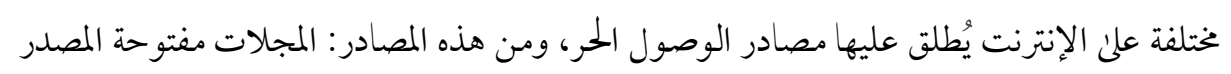

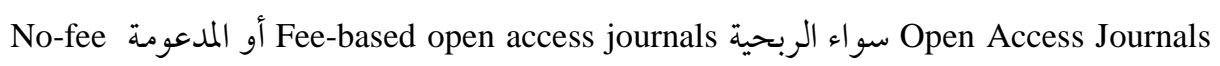


Digital open access journals والأرشيفات الشخصية Self-Archiving، والمستودعات الرقمية .Repositories ووفقاً لنتائج بحث طارق الورفلي ومحمد بن رمضان (r ا • ع) عن واقع الأرشيفات المفتوحة في الوطن العربي تبين أن عددها لا يزال دون المستون المطلوب، وأرجع الباحثان السبب في ذلك إما

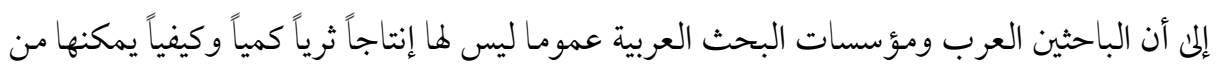
إنشاء مستودعات أرشيفات مفتوحة، أو أن هؤلاء الباحثون يلجؤون إلى الإيداع في المستودعات الغربية الأكثر تأثيراً في الأوساط الأكاديمية لجعل بحوثهم أكثر مشاهدة (الورفلنا وبن رمضان، .$(0 \Lambda, r \cdot 14$

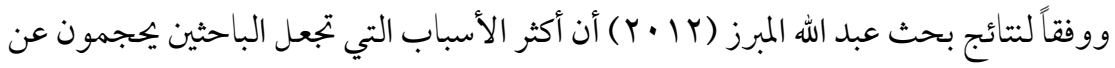
نشر دراساتهم في مصادر الوصول الحر قبل نشرها في أي مصدر آخر من وجهة نظرهم، هي أن تلك المصادر لا تخضع للتحكيم العلمي من قبل هيئة علمية متخصصة، وأن تلك المصادر غير مقبولة في الترقيات العلمية، وأن تلك المصادر لمر تحظى بعد بالسمعة الحسنة، فضلاً عن ضعف المستوئ العلمي للدراسات التي تنشر في تلك المصادر، والخوف من سرقة العمل الفكري وعدم الإشارة إلى مصدره (المبرز، (I)

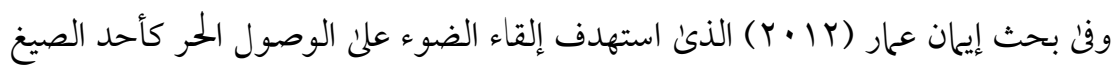
الجحيدة لنشر البحوث العلمية، وذلك من خلال التعرف على العوامل التي ساعدت على ظهوره و انتشاره ومفهومه وآلياته وفلسفته والمبادرات التي دعت إلى تبنى استخدامه، واتجاهات الباحثين العرب والتربويين المصريين نحو استخدامه، كانت أبرز النتائج أن نظام الوصول الحر لمصادر

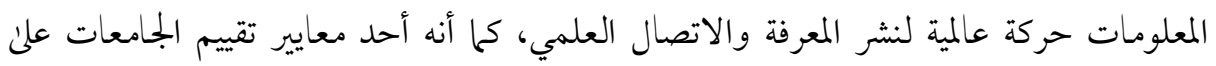
المستوى العالمي، وضعف أداء المجتمع الأكاديمي العربي فيها يتعلق بمؤشرات النشر العلمي، كما تشير النتائج أن الباحث العربي غير مواكب بها فيه الكفاية للتطورات التي تحدث في مجال النشر العلمي

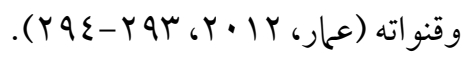

http://dx.doi.org/10.29009/ijres.2.3.7 
وفقاً لبحث لبان والدبيان (· · ( ) للتعرف علن واقع حركة الوصول الحر للمعلومات في

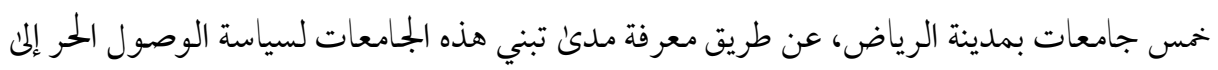

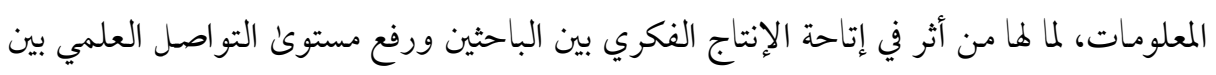

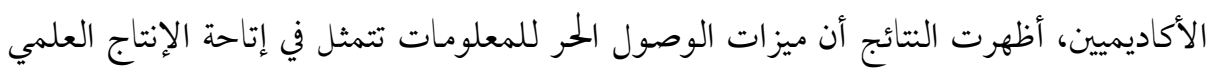

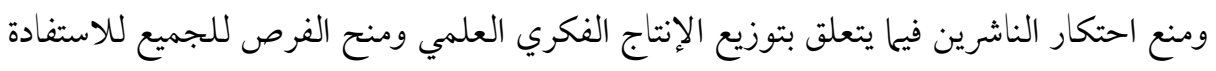

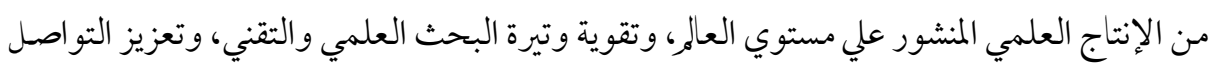

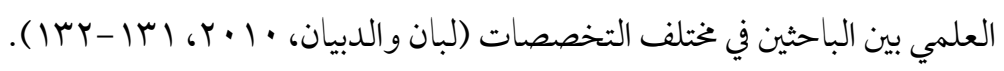

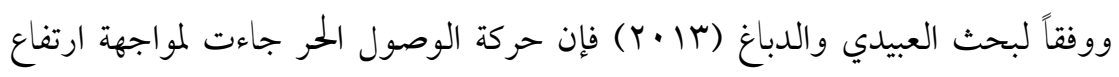

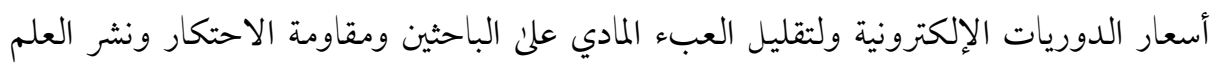

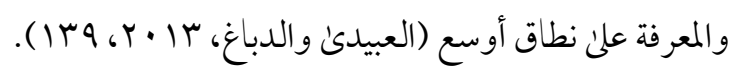
عيوب مصادر الوصول الحر:

أظهرت نتائج لبان والدبيان (· · (Y) أن من أهم المعوقات التي تعوق حركة الوصول الحر

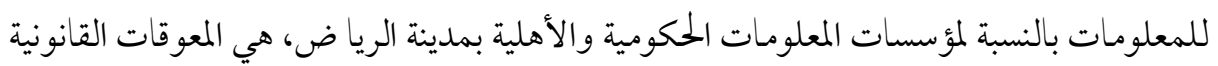

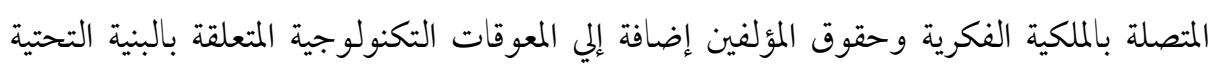

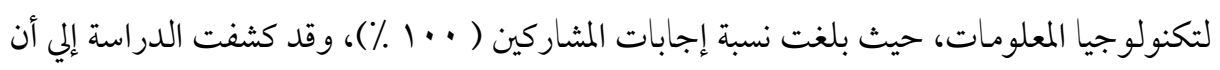

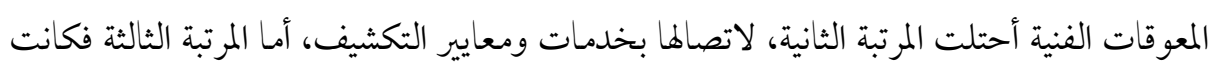

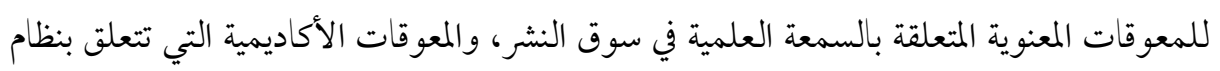

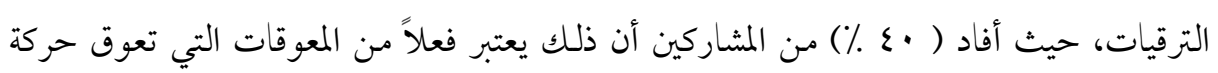

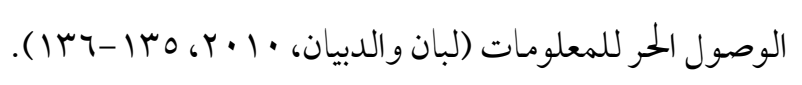




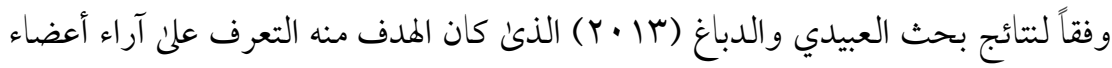
هيئة التدريس بجامعة الموصل عن دور الوصول الحر للمعلومات في تعزيز حركة البحث العلمي، تبين ضعف ومحدودية اطلاع أفراد العينة علن مفهوم الوصول الحر للمعلومات ومبادراته، إذ بلغت

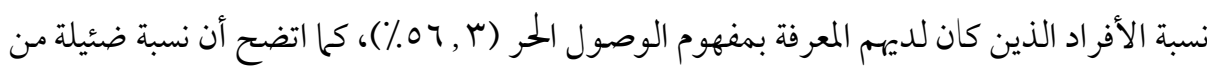

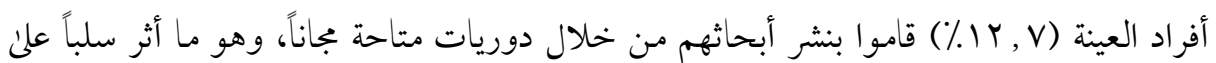

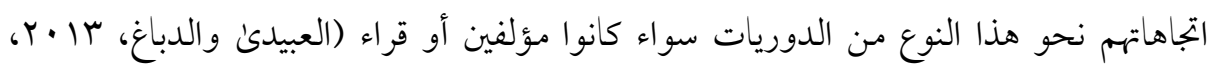

.$(1 r q$

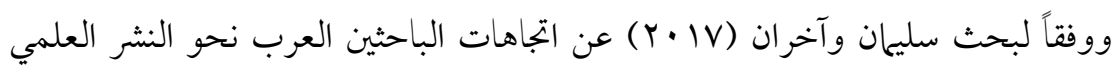
باللغة العربية في مصادر الوصول الحر من وجهة نظر أعضاء هيئة التدريس والباحثين العرب بجامعة الملك فيصل، تبين أن أهم أسباب ندرة النشر العلمي باللغة العربية هي عدم الاعتراف به في أنظمة التوظيف والترقيات الأكاديمية ومنح تمويل البحوث، ولأنه لا يخظى بتقدير واحترام كاف في الوسط الأكاديمي من حولمه، ولأن نسبة الاستشهاد بالبحوث المنشورة باللغة العربية في مجال تخصصاتهم

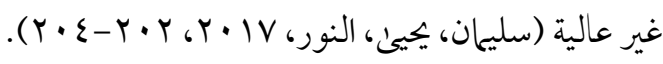

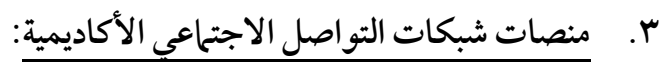

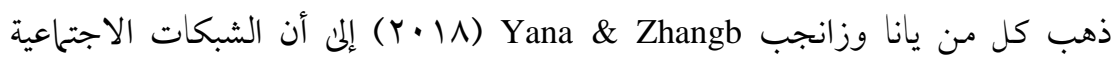
الأكاديمية يمكن أن تكون بمثابة مؤشرات يمكن الاستعانة بها في تقييم أنشطة البحث في الجامعات،

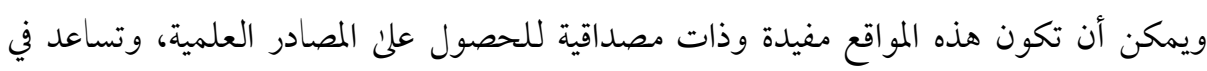
التعرف على نتائج البحوث، وتساعد على النمو الأكاديمي (Yana \& Zhangb, 2018, 397). وعلن الرغم من أن التضخم الكبير في حجم النتاج الفكري بمختلف لغاته يشكل تحدياً كبيراً يو اجه الباحثين والأكاديميين في البحث عن المعلومات والحصول عليها، إلا أن ظهور شبكات 
التواصل الاجتماعي المتنوعة التي عززت التواصل بين الباحثين لنشر وتبادل مساهماتهم العلمية مثل GesearchGate، Scholar

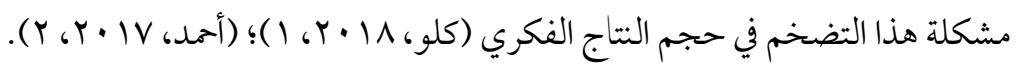
ووفقاً لنتائج بحث أمما (Y. (Y) حول دور منصات شبكات التواصل الاجتاعي الأكاديمية في تعزيز حركة النشر العلمي، تبين أن هذه المنصات تمارس دوراً فعالاً في تطوير آليات

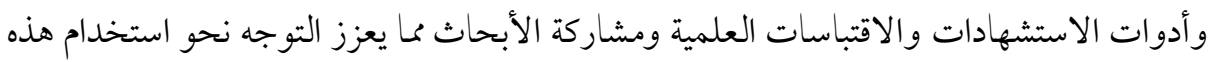
المنصات، وتبين وجود اختلافات في الرؤين والسياسات التي تنتهجها المنصات عينة الدراسة فيا يتعلق بإدارة المحتون، وإتاحته، وطبيعة الخدمات التفاعلية المتاحة للمستخدمين، وبالتالي يعتمد اختيار الباحثين للمنصة علن الاحتياجات المعلوماتية وطبيعة الحدمات التي يكون هناك حاجة إليها،

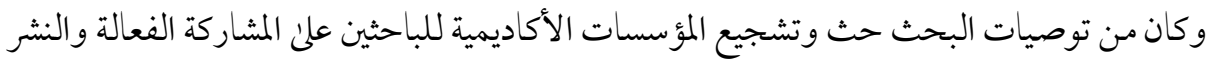

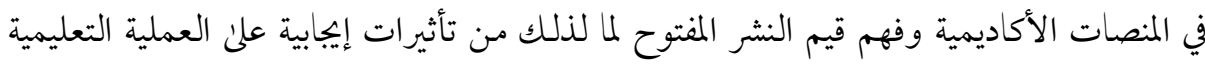
والبحثية، كم ينبي ترتيب دورات وورش عمل تعريفية بشبكات التواصل الاجتماعي الأكاديمية

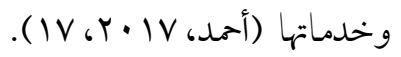

كيزات منصات شبكات التواصل الاجتماعي الأكاديمية:

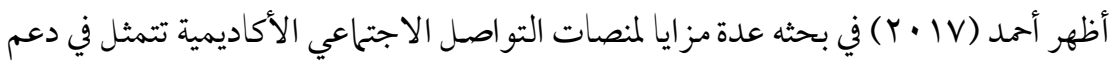

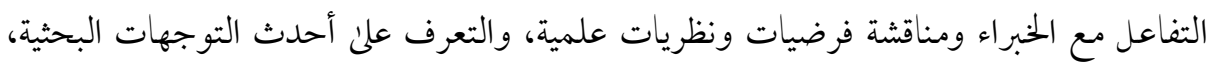
والمساعدة في التوصل لحلول مقبولة للمشاكل العلمية، وتعزيز نشر المخرجات البحثية (أمد، .$(17-V, r+1 V$

وأظهرت نتائج بحث كلو (1) · (Y) أن هذه المنصات ليست بجرد شبكة تواصل بين الباحثين

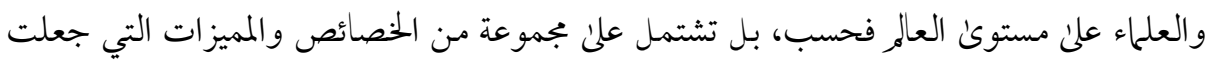

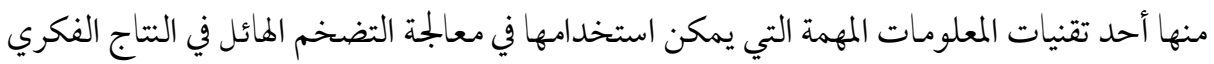


وذلك من خلال قدرتها علن حصر وتنظيم النتاج الفكري المنشور فيها وبكل أنواعه ولغاته وتخصصاته، وحفظ النتاج الفكري المنشور فيها والتمكين من إتاحته بجاناً لمن يحتاج إليه من

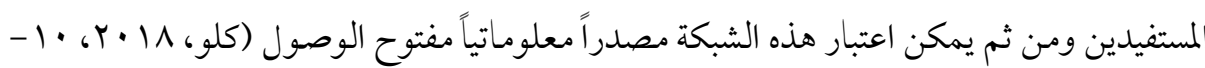

\section{عيوب منصات شبكات التو اصل الاجتحاعي الأكاديمية:}

تبين من خلال بحث أحمد (Y (Y) عدة عيوب لمنصات شبكات التواصل الاجتماعي الأكاديمية منها استهلاك الكثير من الوقت، وصعوبة التعرف علن أو اختيار المنصة التي تلبئ احتياجات الباحث، وقلة عدد المشاركين النشيطين، وبروز ما يتعلق بقضايا حقوق الملكية الفكرية الخاصة بالمحتوكي، وهناك تأثيرات سلبية علن المؤسسات الأكاديمية مثل انتشار المعرفة التي يمكن استخدامها بو اسطة جهات أكاديمية أخرى منافسة، وإمكانية تحليل معدل استخدام منسوبي المؤسسة

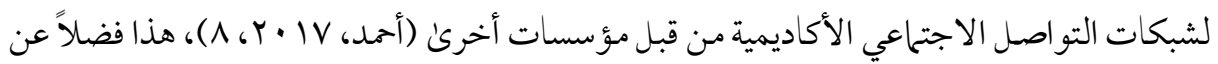
المشكلات التي تتعلق بالحفاظ على خصوصية معلومات المستخدم وأمانها، خاصةً عندما يكون المحتوى الذي تم تحميله بواسطة المستخدم عبارة عن وسائط متعددة، مثل الصور ومقاطع الفيديو والتسجيلات الصوتية (Rathore, Sharma, Loia, Jeong, \& Park, 2017, 65). ثانياً: الاتجاهات الحديثة من حيث موضوعات النشر: لجأ الخبراء والباحثون في مجال أصول التربية إلى السعي نحو وضع خريطة بحثية للباحثين في

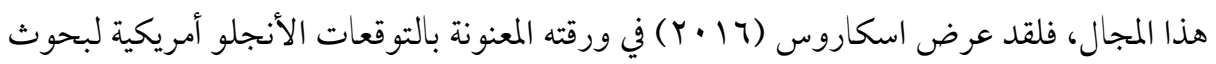
أصول التربية في المستقبل القريب، التي استند فيها علن ما توصل إليه \ل متخصصاً في أصول التربية ينتمون لجامعات مختلفة أغلبها إنجليزية وأمريكية، حيث قاموا بتقويم المتاح من المنشور باللغة الإنجليزية في شتى فروع أصول التربية حتى سنة || + ب، ثم قدموا مؤشرات لتوقعات عن بحوث أصول التربية في المستقبل القريب، فقام بعرض بعض التوقعات المستقبلية للبحوث في مقابل البحوث

\section{http://dx.doi.org/10.29009/ijres.2.3.7}


التقليدية، وذلك في عدة بجالات هي: الأهداف التربوية، والخبرة التربوية، والطبيعة البشرية، والتربية الخلقية، والظهير الفلسفي للممارسات التربوية الناجحة، والأصول التاريخية للتربية، والأصول الاجتماعية للتربية، والأصول الجغرافية للتربية، والأصول السيكولوجية للتربية (إسكاروس،

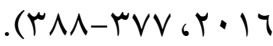

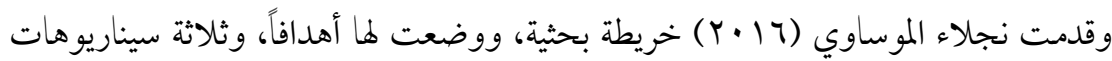
للتنفيذ هي: السيناريو المحافظ، والسيناريو التقدمي، والسيناريو التطويري المتقدم، ووجدت أن هناك فجوات بحثية تحتاج إلى توجيه البحث العلمي نحوها وأرجعت تجاهل الباحثين لهذا النوع من البحوث إلى نقص معرفتهم بمناهج البحث اللازمة لدراستها، ولذا أوصت بضرورة اختيار المواضيع البحثية وفقاً للمستجدات والقضايا والاحتياجات الملحة مع مراعاة العمل على تزويد الباحثين بالمهارات

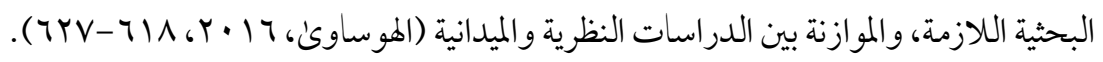

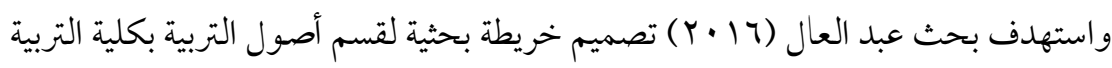
جامعة بنى سويف في ضوء الأولويات البحثية، وتوصل البحث إلى أنه لبناء خريطة بحثية متكاملة الأركان لابد من الارتكاز علن بجموعة من العناصر التي تمثل محددات لعمل البحث العلمي التربوي داخل القسم، وهي: مقومات الانضمام لمجتمعات المعرفة، والاحتياجات البحثية للمجتمع، وأبعاد ومؤشرات خطط التنمية، وفي ضوء هذه المرتكزات تم تحديد عدد من الموضوعات داخل المجالات البحثية المختلفة للقسم، كما توصل البحث إلى وجود عدد من المعايير التي تحدد الأولويات البحثية لهذه الموضوعات، ومن أهمها معيار الأهمية ومعيار ندرة الدراسة، ومعيار الارتباط باحتياجات التنمية، وفي ضوء المرتكزات والمعايير تم وضع مصفوفة بالأولويات البحثية التي يجب إدراجها في الخريطة البحثية داخل كل مجال من مجالات قسم أصول التربية بكلية التربية في جامعة بنى سويف

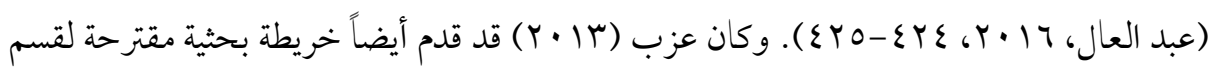
أصول التربية بكلية التربية بالزقازيق تضمنت العديد من الموضوعات المرتبطة بأصول التربية (عزب، 
ثالثاً: الاتجاهات الحديثة من حيث تجويد النشر لبحوث أصول التربية ورفع كفاءة الباحثين: تو جد عدة اتجاهات تُعين على تجويد النشر لبحوث أصول التربية لعل من أهمها ما يأتي:

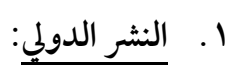

يُمثل النشر الدولي أحد الاتجاهات التي تُعين علن تجويد مستوكئ النشر للبحوث العلمية، بل إنه يُعد مؤشراً تُصنف الجامعات في ضوئه، لما يتضمنه من نشر نتائج الأبحاث العلمية في الدوريات العلمية العالمية المحكمة من قِبل أساتذة متخصصين في فروع العلوم والآداب المختلفة. ففي بحث

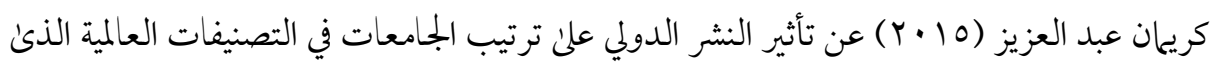
اتخذت من جامعة القاهرة نموذجاً، أظهرت فيه أهمية النشر الدولي كمعيار لتصنيف الجامعات عالمياً وفقاً لمعايير أشهر التصنيفات العالمية للجامعات (عبدالعزيز، 10 • r).

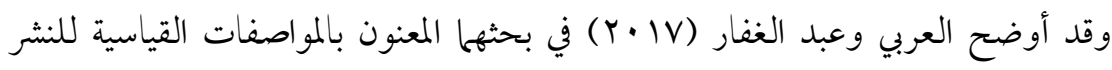
الدولي، كل ما يتعلق بالمعايير التي ينبغي أن يراعيها المؤلفون والمحررون والناشرون فيها يتعلق بالنشر في الدوريات العلمية، من الناحيتين الشكلية والفنية بالتفصيل، وذلك لتعظيم الاستفادة من هذه

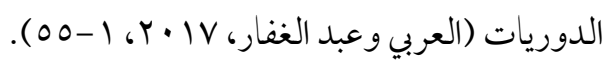

ووفقاً لنتائج بحث رضوان (Y IV) الذئ استهدف حصر ووصف الإنتاج الفكري المنشور دولياً والمكشف بقاعدة بيانات سكوبس Scopus للباحثين بالمر اكز والمعاهد البحثية المصرية ومقارنتها بحجم الإنتاج الفكري المنشور دولياً للباحثين بالجامعات المصرية الحكومية، تبين تزايد حجم الإنتاج الفكري المنشور دولياً، فقد كانت النسبة r , • ب في العقد ( 1901 - • • 197 ) وازدادت لتصبح

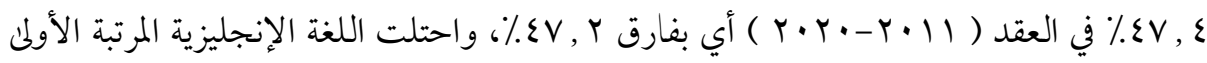
علن مستوكئلغات نشر الأبحاث الدولية بنسبة ا ,99٪ باعتبارها لغة النشر العالمية الأولن في الشكل الإلكتروني، واحتل النشر في قطاع العلوم الطبيعية المرتبة الأولى بنسبة ا ,7؟ء٪، يليه قطاع العلوم الهندسية في المرتبة الثانية بنسبة و , و ؟٪، وجاء في المرتبة الثالثة الأبحاث المنشورة في قطاع العلوم 
الطبية بنسبة 9 , ع 1٪؛ أما عن الأبحاث المنشورة في قطاع العلوم الزراعية والاجتماعية والإنسانية

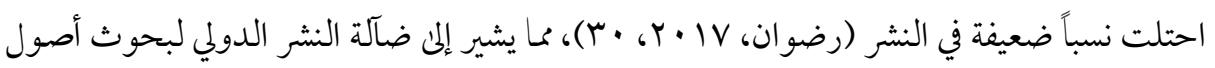
التربية في حالة وجودها.

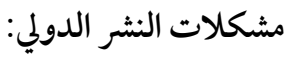

تعد مشكلة الاحتيال في النشر العلمي كالمجلات والدوريات الوهمية أحد أهم المشكلات التي تتعلق بالنشر الدولي. لذا تجدر الإشارة إلى ضرورة التأكد من رصانة الدورية أو المجلة قبل النشر لوجود دوريات زائفة تفرض رسوماً للنشر دون القيام بتحكيم حقيقي للبحوث. حيث بينت نتائج

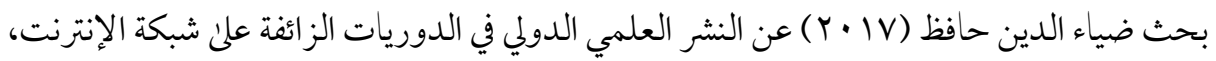
أن أكثر الدول التي تتركز فيها الدوريات الزائفة هي الهند وباكستان وأمريكا ونيجيريا، وأن المقالات العربية تمثل 10 بـ من إجمالي عدد المقالات المنشورة بتلك الدوريات، وتتصدر مصر والعراق والسعودية قائمة الدول العربية التي وقع باحثيها ضحية النشر في هذه الدوريات (حافظ، IV. V،

\section{Y. النشر في مصادر لها معاملات تأثير وفق معايير عالمية:}

وفقاً للدهشان (1) · r) فإن معامل التأثير هو مقياس يوضح أهمية الدوريات العلمية في مجال تخصصها، وفقاً لإشارة الأبحاث الجديدة إلم ما هو منشور سابقاً في تلك الدوريات واستشهادها بها، بها يعني أهميتها وملاقاتها للقبول عند أهل التخصص، وبو اسطته يتوفر التقييم الكمي والنوعي اللازم

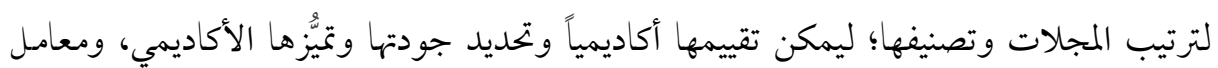
التأثير يُحسب سَنوياً لتلك المجلاتِ التي فهرست في (Journal Citation Report) ويتضمن فقط المجلات التي تفهرس ضمن تقرير طومسون رويترز العلمي Thomson Reuters وهذا يحدث سنوياً، ومُعامل التأثير يُعرف بأنه متوسط عدد المرات التي تم فيها الاستشهاد بورقة البحث عن طريق باحثون آخرون في مراجع أور اقهم البحثية خلال السنتين الماضيتين، أو خلال الأربع سنوات الماضية 


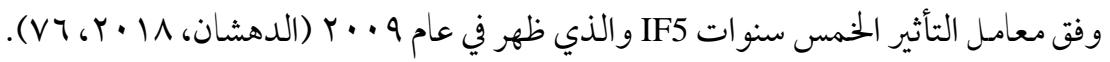
تحث الجامعات أعضاء هيئة التدريس بها علن نشر بحوثهم في مصادر لها معاملات تأثير وفق معايير عالمية عن طريق تقديم حوافز مادية ومعنوية لتبو أ هذه الجامعات ترتيباً متقدماً في التصنيفات العالمية للجامعات. غير إنه في حقيقة الأمر حتى الآن لا توجد دوريات أو مجلات منشورة باللغة العربية ذات معامل تأثير، ولما كان أغلب الإنتاج العلمي للباحثين العرب في مجال العلوم التربوية مكتوباً باللغة العربية، فإن نشر بحوث أصول التربية المكتوبة باللغة العربية في مصادر لها معامل تأثير غير متاح في الوقت الحلالي، لذا ظهرت جهود تدعو إلى ضرورة وجود معامل تأثير عربي للدوريات والمجلات المنشورة باللغة العربية والتي في غالبيتها تنتمى للعلوم الاجتماعية والتربوية، ولقد ساق

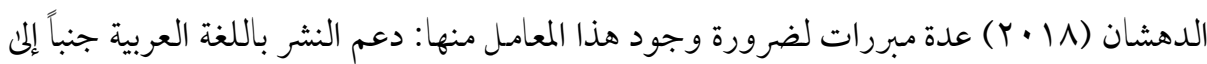
جنب النشر باللغة الإنجليزية تأكيداً لأهمية الاعتزاز بالهوية العربية والحفاظ على جهود الباحثين العرب، وتشجيعهم علن إجراء البحوث ذات الصبغة المحلية أو التي تهم القارئ العربي والتي قد لا

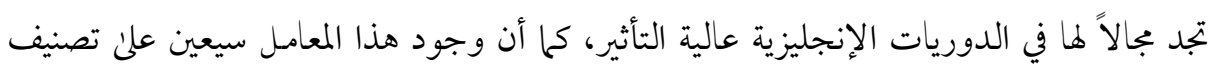
الدوريات العربية وما يترتب علن ذلك من المساعدة في تقييم بحوث أعضاء هيئة التدريس عند تقدمهم للجان الترقيات العلمية، ورفع كفاءة الإنتاج البحثي المكتوب باللغة العربية، فضلاً عن

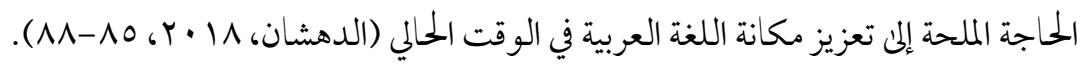

\section{r. إخضاع البحوث العلمية لبرامج فحص الانتحال:}

يعتبر فحص البحوث العلمية ضد الانتحال العلمي من أهم الإجراءات التي تُعين علن تحسين مخرجات البحث العلمي والحفاظ علئ السمعة الأكاديمية للباحثين ومؤسساتهم في الأوساط العلمية، وعلن ذلك نصت قواعد الترقيات بالمجلس الأعلى للجامعات المصرية في دورتها الثانية عشر

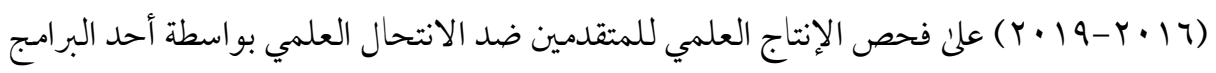
بوحدة المكتبة الرقمية بالمجلس الأعلن للجامعات أو برامج مشابهه بالجامعات المصرية، ووفقاً لأبو

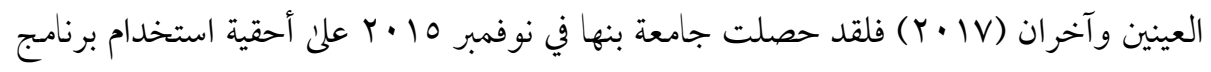


من من أكاديمية البحث العلمي كأداة لمنع الانتحال العلمي، وصدر قرار بهذه الجلمعة يتضمن ضرورة فحص رسائل الماجستير والدكتوراه ضد الانتحال العلمي قبل الموافقة على تشكيل

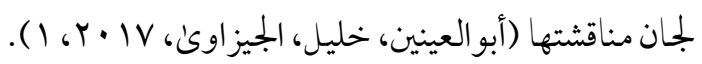
ويعد برنامج iThenticate من أشهر برامج كشف الانتحال العلمي في البحوث العلمية، ويساعد الباحثين والمؤسسات التعليمية والبحثية ودور النشر والمجلات العلمية علن تحسين جودة خرجات البحث العلمي وحماية حقوق الملكية الفكرية للإنتاج العلمي، لدقته في التعرف على الانتحال والتشابه في البحوث والرسائل العلمية (أبو العينين، خليل، الجيزاوىن، VI • Y، I ). أظهرت نتائج بحث أبو العينين وآخران (Y PV) عن فاعلية برنامج iThenticate في منع الانتحال وتحسين جودة خخرجات البحث العلمي لدى طلاب الدراسات العليا بجامعة بنها، انخفاض نسبة التشابه وانتحال الاقتباسات في الانتاج الفكري لطلاب الدراسات العليا بجامعة بنها عند استخدام البرنامج كأداة لمنع الانتحال العلمي في النصف الثاني من العام الدراسي مقارنة بالنصف الأول من ذات العام، وبينت النتائج أيضاً انخفاض نسبة التشابه في الإنتاج الفكري لطلاب

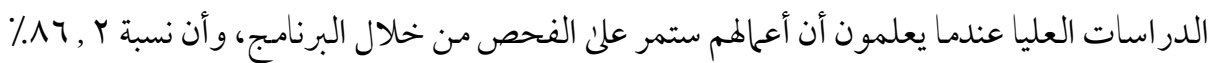
من طلاب الدراسات العليا يفضلون فحص إنتاجهم الفكري من أبحاث علمية علن البرنامج قبل إرساها للمجلات العلمية (أبو العينين، خليل، الجيزاوين، V I · Y، 10 ).

\section{ع. إجر اء البحوث الجماعية أو بحث الفريق:}

حيث يؤكد أحمد البنا (ع ( · r) في بحثه المعنون ببحث الفريق كمدخل لضمان جودة البحث التربوي في كليات التربية المصرية، علن ضرورة التوجه نحو بحث الفريق أو البحوث الجماعية في إجراء البحوث التربوية لما في ذلك من تكامل لدراسة المشكلات التربوية من جميع جو انبها، وضرورة وضع خرائط بحثية بكليات التربية تحدد بجالات بحوث الفريق، ليلجأ إليها الراغبين من طلاب الدراسات العليا وأعضاء هيئة التدريس، وكذا توفير الإمكانات المادية اللازمة، والمناخ الأكاديمي 
والنفسي والاجتماعي الملائم، والتشريعات المشجعة علن البحث الجماعي في المؤسسات التربوية

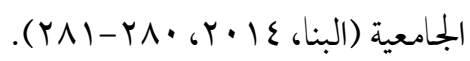

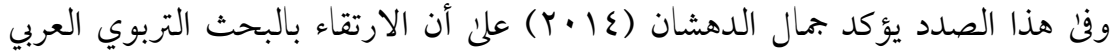
يتطلب التوسع في إجر اء الدراسات البينية التي تجمع تخصصات مختلفة فكثير من القضايا والمشكلات التربوية يصعب حصرها في تخصص واحد لتعدد أبعادها ومتغيراتها وتشابكها (الدهشان، ع ا ب ؟،

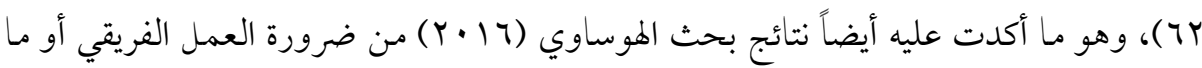
يسمى بالبحوث البينية مع أقسام كليات التربية، ومع أقسام من خارجها، كالبحوث البينية بين قسمي أصول التربية والإدارة التربوية، وقسم أصول التربية وقسم علم النفس التربوي، وقسم أصول التربية

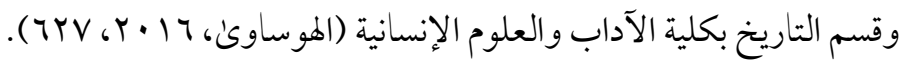

\section{ه. إشر اك طلاب الجامعة في النشر العلمي:}

هناك توجه لإشراك طلاب الجامعة في النشر العلمي لاستثمار قدراتهم العلمية وتنمية مهاراتهم البحثية وصقلها، حيث أكدت هند الخليفة ( اسع 1 هـ) في بحثها المعنون باستعر اض تجارب محلية وعالمية لإشراك طالبات البكالوريوس في النشر العلمي والمؤتمرات الدولية، علن ضرورة التوجه نحو إشراك طلاب الجامعة في النشر العلمي، حيث يتميز معظم الطلبة في هذه المرحلة بسهولة اكتسابهم للمعارف وحماسهم للتعلم، مما يعني طاقات بشرية يمكن استثمارها إذا ما توفرت الفرص البحثية المناسبة، فضلاً عن أن إدماج طالب الجامعة بالبحث العلمي وتجربته المشاركة في المؤتمرات وحضور حلقات النقاش والتعرف على باحثين من دول مختلفة، يؤدن إلى صقل شخصيته كطالب جامعي وكباحث مستقبلاً، ويولد لديه شعوراً بأهمية البحث العلمي ودوره في تقدم الأمم، كما يسهم في تشجيعه علن إكمال دراسته العليا، وأوصت بأن تتضمن الخطط الدراسية ساعات بحثية تشمل إشراك الطلاب في الأوراق العلمية أو الملصقات الجحدارية في المؤتمرات المحلية والدولية، وتحصيص ميزانية تُعين الطلاب علن الحضور والمشاركة في المؤتمرات، وكذا التأكيد علن إكساب الطلاب مهارات البحث من خلال المحاضرات اليومية، وتقديم التقدير المناسب للأساتذة الداعمين للطلاب الباحثين 
(الخليفة، اباعا هـ، 1 +7)، وفن ضوء ذلك يمكن العمل علن إشراك طلاب كلية التربية في النشر العلمي.

خاتمة:

تبين مما تقدم أن هناك عدة اتجاهات للنشر العلمي يمكن الاستفادة منها في النشر في بجال

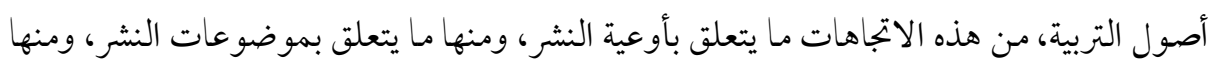

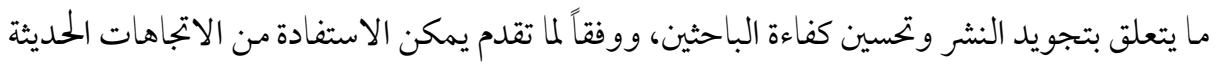
في النشر العلمي للبحوث التربوية وبخاصة في بجال أصول التربية، من خلال ما يأتي: 1- إكساب الباحثين الكفايات اللازمة للاستفادة من الإنترنت والتكنولوجيات الحديثة في

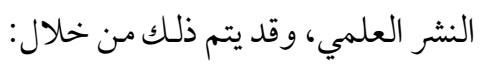

أ- عقد دورات تدريبية لأعضاء هيئة التدريس والباحثين في مجال أصول التربية بهدف

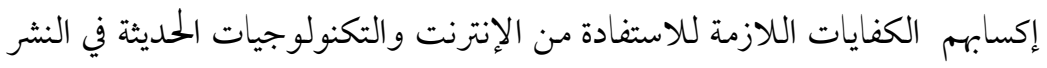
العلمي ب- تنظيم ورش عمل لأعضاء هيئة التدريس بحيث يمكن من خلالاها الاستفادة من ذوين الحبرة في بجالات النشر العلمي الحديثة.

r- تشجيع الباحثين علن النشر الإلكتروني علن الإنترنت، ويمكن أن يتحقق ذلك عن طريق: أ- عقد ندوات تعريفية بالنشر الإلكتروني وميزاته وعيوبه وكيفية استفادة الباحثين من المميزات وتجنب العيوب.

ب- عقد مؤتمرات تتناول البحث في كيفية الاستفادة من الإمكانات المتاحة علن الانترنت لخدمة النشر العلمي. r- ت توعية الباحثين بمشكلات النشر الدولي كالدوريات الوهية أو الزائفة، ويمكن أن يكون 
ذلك من خلال:

أ- تنظيم ندوات ومؤتمرات يتم من خلالها تناول مشكلات النشر الدولي بالدراسة

و البحث.

ب- الإعلان عن الدوريات الرصينة وحث الباحثين علن النشر فيها.

ع - تنمية مهارات الباحثين لمواجهة الانتحال العلمي، ويمكن أن يتم ذلك عن طريق:

أ- عقد دورات تدريبية للأكاديميين والباحثين على مهارات البحث العلمي والكتابة

العلمية.

ب- عقد ورش عمل للأكاديميين يتم من خلالها التعرف علن الممارسات الجيدة للباحثين

الجيدين.

ه- تشجيع الباحثين علن النشر في مصادر لها معاملات تأثير وفق معايير عالمية، ويمكن أن يتم

$$
\text { ذلك عن طريق: }
$$

أ- تخصيص مكافآت نشر لأعضاء هيئة التدريس الذين ينشرون بحوثهم في مصادر ها

معاملات تأثير عالية.

ب- إعطاء الباحثين شهادات تقدير في حالة نشر بحوثهم في الدوريات العلمية الرصينة.

7- تشجيع الباحثين علن الاستفادة من منصات التواصل الاجتاعي الأكاديمية في النشر

العلمي، وقد يتحقق ذلك من خلال:

أ- عقد ندوات تعريفية بمنصات التو اصل الاجتماعي الأكاديمية للباحثين بحيث يمكنهم

الاستفادة من مميزاتهاوتجنب سلبياتها.

ب- تنظيم ورش عمل للأكاديميين بغرض نشر الخبرات الجيدة المرتبطة بمنصات التواصل

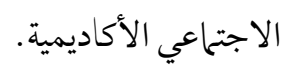

\section{http://dx.doi.org/10.29009/ijres.2.3.7}




\section{المراجع العربية}

I. أبوالعينين، هاشم محمد؛ خليل، ماهر حسب النبي؛ والجيزاوين، ناصر خميس. (V) (Y).

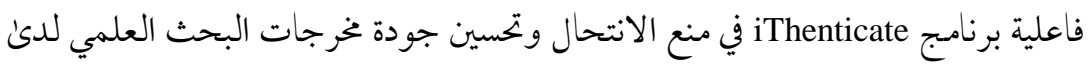

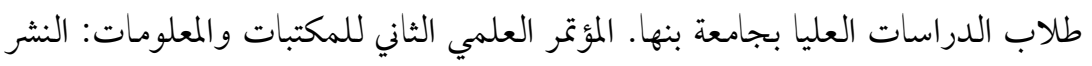

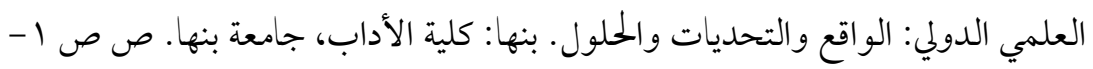

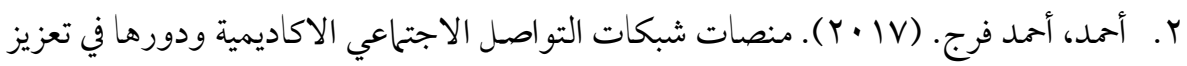

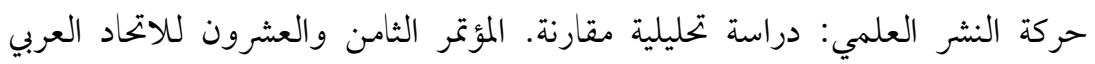

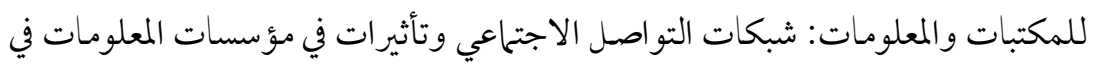

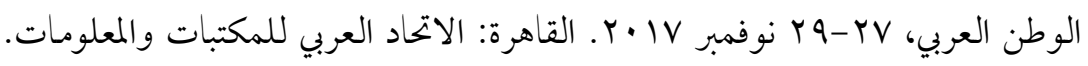

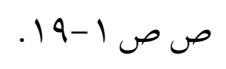

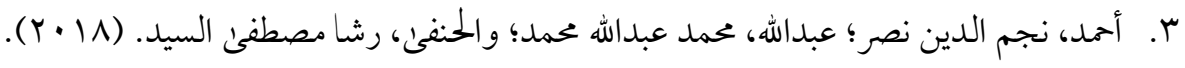

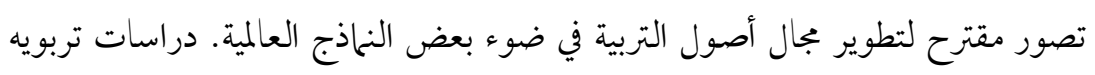

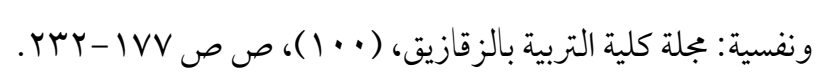

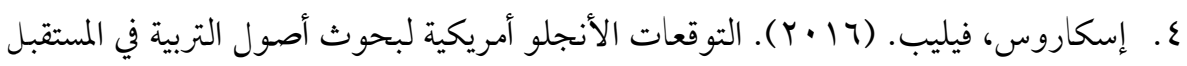

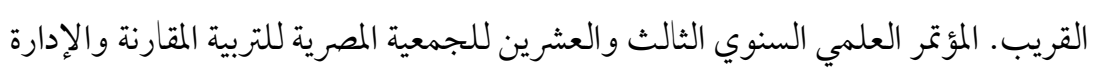

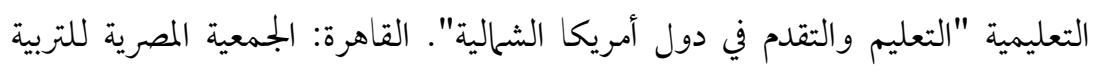

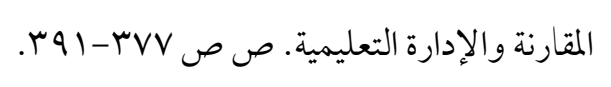

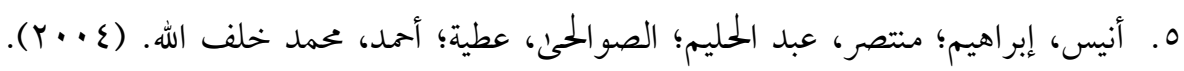
المعجم الوسيط. ط ع. القاهرة: مكتبة الشروق الدولية.

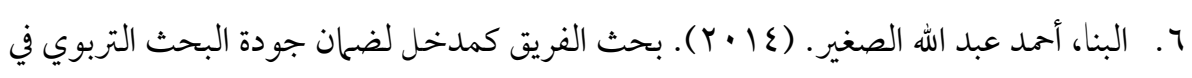

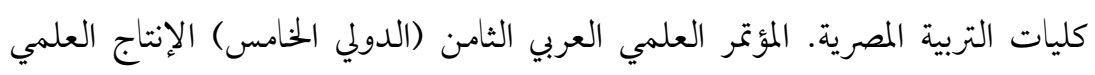


التربوي في البيئة العربية القيمة والأثر. سوهاج: كلية التربية، جامعة سوهاج. ص ص

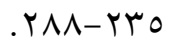

V. حافظ، ضياء الدين عبد الواحد. (يناير، IV P). النشر العلمي الدولي في الدوريات الزائفة

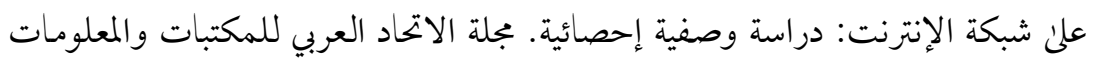

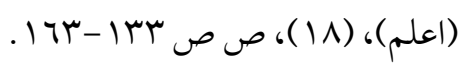

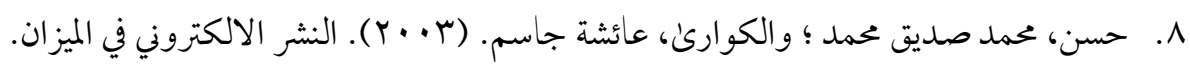

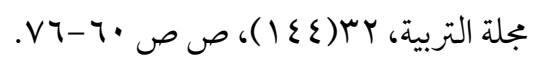

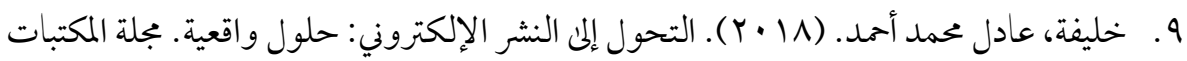

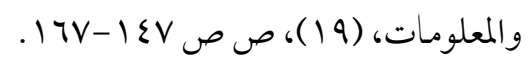

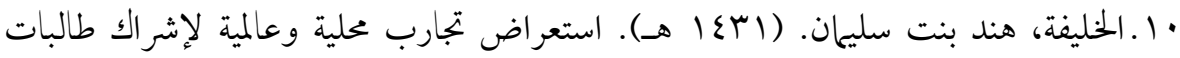

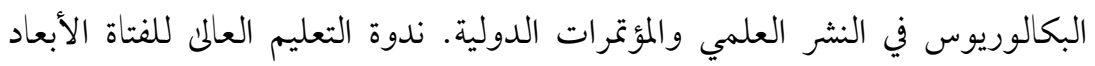

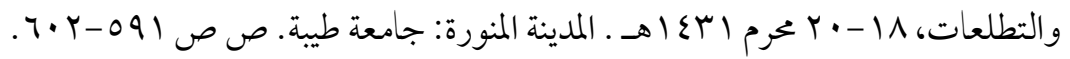

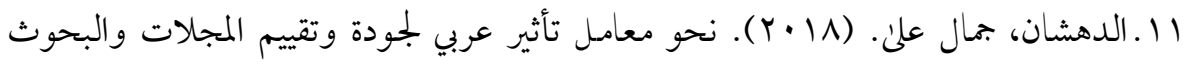

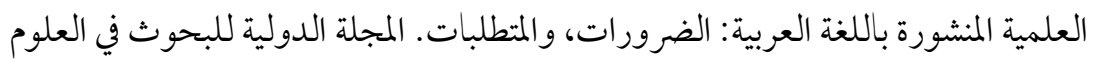

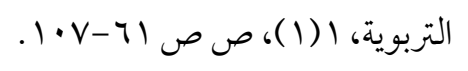

r ا ـ الدهشان، جمال علن. (ع ا • Y). ملامح رؤية مقترحة للارتقاء بالبحث التربوي العربي. المؤتمر

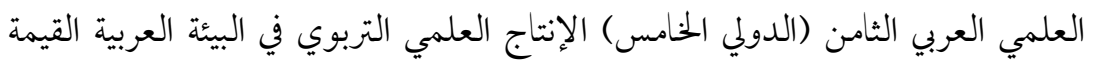

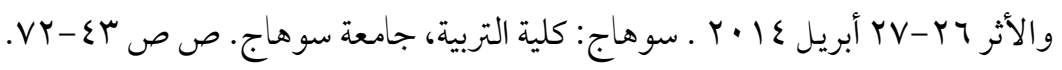

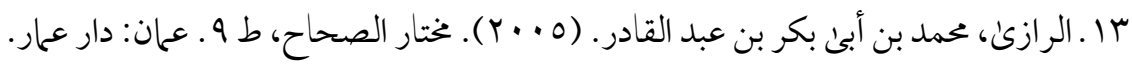

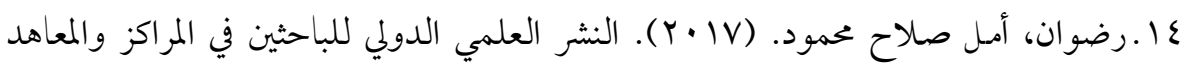

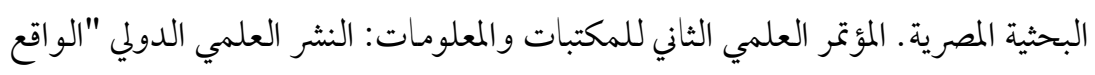

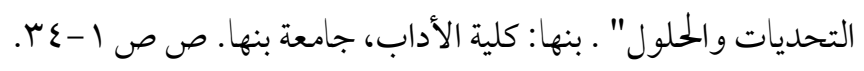




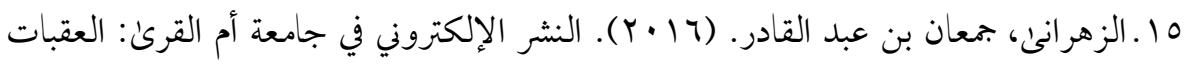

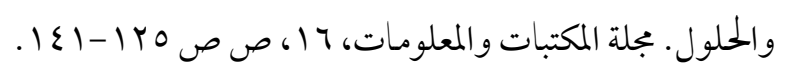

7 ا ـ السرحانئ، وفاء فاهد. (r ( • (Y). النشر الإلكتروني و البحث العلمي. دراسات عربية في التربية

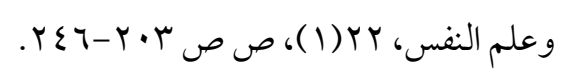

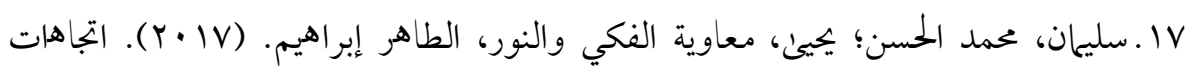
الباحثين العرب نحو النشر العلمي باللغة العربية في مصادر الوصول الحر: دراسة مسحية المعنية في جامعة الملك فيصل. مجلة المركز العربي للبحوث والدراسات في علوم المكتبات

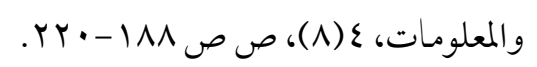

1 ا الشاذلي، نهال أحمد عبدالقادر؛ ومحجوب، حسناء محمود أحمد. (YV) (Y). النشر العلمي في جامعتي المنوفية والملك سعود وتأثيره علن الترتيب العالمي للجامعتين. المجلة الدولية لعلوم

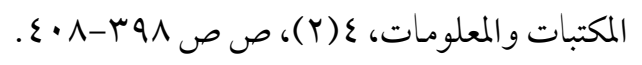

9 1.شاهين، شريف كامل. (ديسمبر، 1| (Y). عشوائية المعلومات علن الشبكة العنكبوتية (الويب). Cybrarians Journal r.

\&http://www.journal.cybrarians.org/index.php?option=com_content catid=251:2011-11-28-21-18-\&id=601:2011-12-01-22-02-06\&view=article

Itemid=87\&27

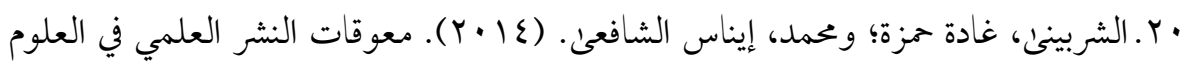

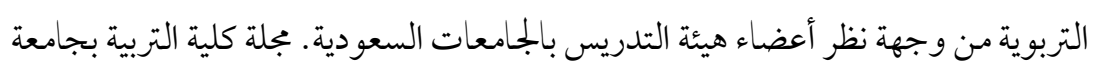

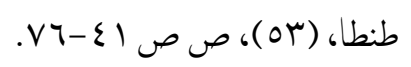

ا Y. عبدالعال، نجلاء عبدالتواب عيسى. (Y (Y (Y). تصميم خريطة بحثية لقسم أصول التربية بكلية التربية جامعة بن سويف في ضوء الأولويات البحثية. مستقبل التربية العربية،

$$
\text { . Lro-rar }
$$

Y Y.عبدالعزيز، كريمان بكنام صدقي. (مارس، 10 • Y). تأثير النشر الدولي علن ترتيب الجامعات في التصنيفات العالمية: جامعة القاهرة نموذجاً. Cybrarians Journal، 
view=article\&http://journal.cybrarians.info/index.php?option=com_content Itemid=93\&catid=273: studies\&id=688:kareman\& r r. العبيدى'، سيف قدامه يونس؛ والدباغ، رائد عبد القادر حامد. (rا • r). دور الوصول الحر للمعلومات في تعزيز حركة البحث العلمي: دراسة استطلاعية لآراء عينة من أعضاء هيئة

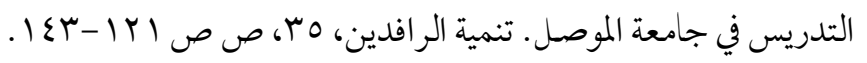

ع r. العربي، أحمد عبادة؛ وعبدالغفار، آلاء محمد. (YV) (Y). المواصفات القياسية للنشر الدولي. أبحاث المؤتمر العلمي الثاني للمكتبات والمعلومات: النشر العلمي الدولي الواقع و التحديات والحلول . مصر: كلية الآداب، جامعة بنها. ص ص 1 1-00.

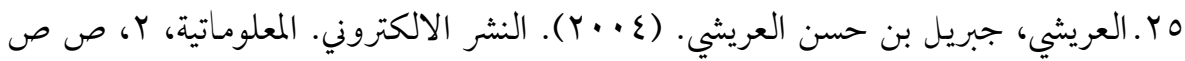
.rO-YI

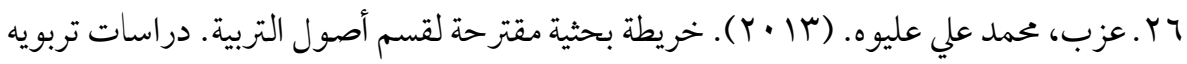
ونفسية: بجلة كلية التربية بالزقازيق، الی، ص ص الح-19.1.

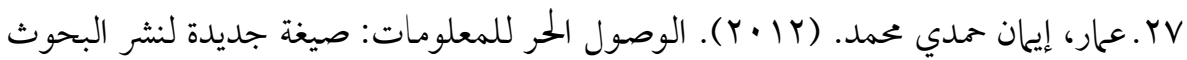
العلمية. المؤتمر العلمي الحادي عشر بعنوان أزمة القيم في المؤسسات التعليمية. الفيوم: كلية

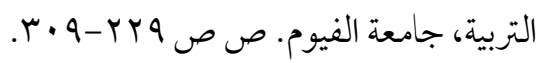

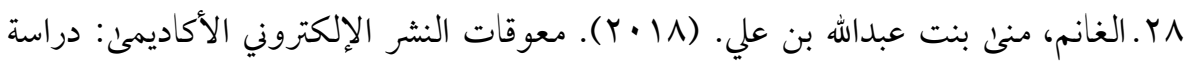

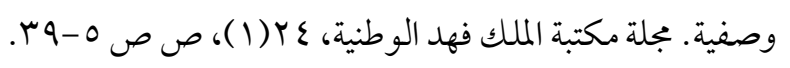

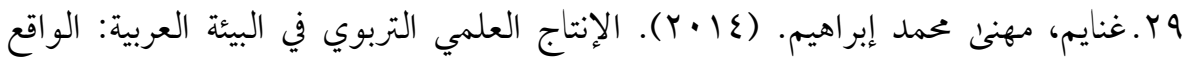
والمأمول. المؤتمر العلمي العربي الثامن (الدولي الخامس) الإنتاج العلمي التربوي في البيئة

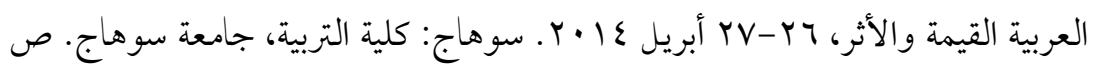

$$
.1 \varepsilon r-1 \cdot 1 \Omega
$$


•r. كلو، صباح محمد. (1) • (Y). شبكة بوابة البحث (Network Gate Research) ودورها في إدارة تضخم النشر العلمي والتو اصل بين الباحثين: أعضاء هيئة في جامعة السلطان قابوس نموذجا. المؤتمر السنوي الرابع والعشرين لجمعية المكتبات المتخصصة فرع الخليج العربي البيانات الضخمة وآفاق استثمارها: الطريق نحو التكامل المعرفي. مسقط: جمعية المكتبات

$$
\text { المتخصصة فرع الخليج العربي. ص ص 1 - -1. }
$$

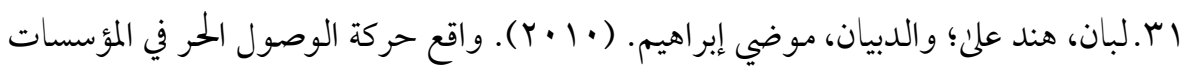

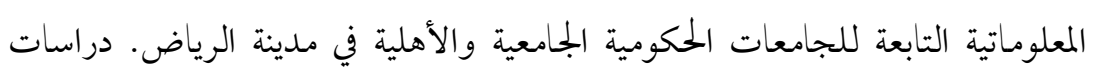

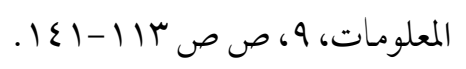

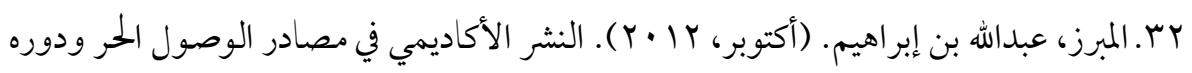

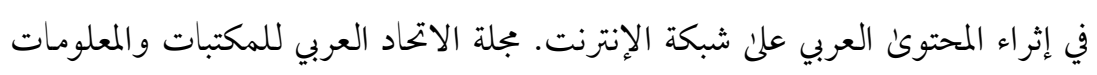

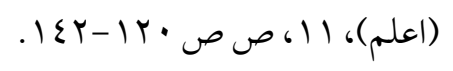

سM. محمد، عزيزة إبراهيم؛ عبدالحكم، إيهان محمد؛ سلامة، أميرة؛ مصطفى، همت؛ وسليمان، رحاب. (Y V · V). النشر العلمي ودوره في النهوض بالبحث العلمي والجامعة. دراسات عربية في التربية وعلم النفس، عدد خاص بأوراق عمل وبحوث المؤتمر الدولي الأول لمركز

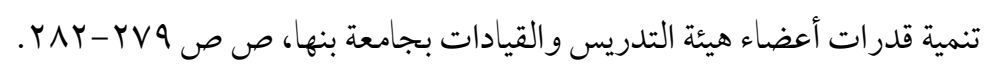

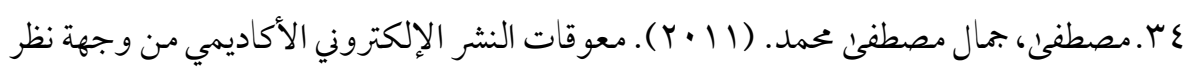
أعضاء هيئة التدريس بالجامعات العربية. مؤتمر المحتوى العربي في الانترنت: التحديات و الطموح ، جامعة الإمام محمد بن سعود الإسلامية، ص ص الب ب-10.

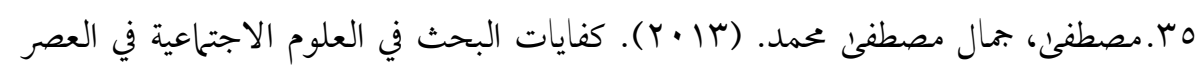

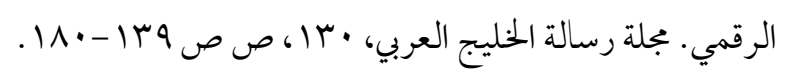


Tr.مصطفى، جمال مصطفى محمد. (Y (Y). العوامل المؤثرة في النشر العلمي في الأوعية الإلكترونية لدئ أعضاء هيئة التدريس بالجامعات العربية من وجهة نظرهم. المجلة

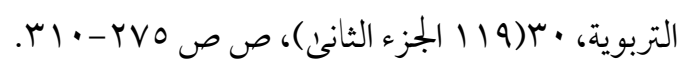

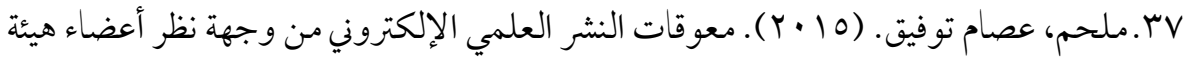

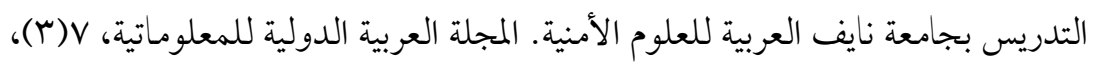

$$
\text { ص ص ص - n }
$$

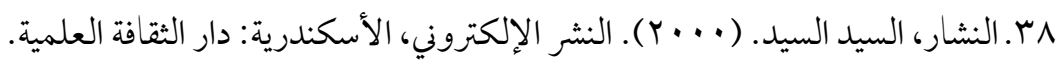

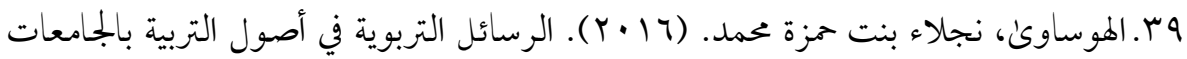
السعودية رؤية مستقبلية لخارطة بحثية. مجلة التربية للبحوث التربوية والنفسية

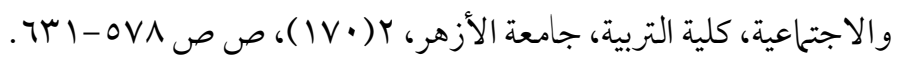

• ع. الهوش، أبو بكر محمود. (1 + ؟Y). التحول من النشر التقليدي إلى النشر الالكتروني. المؤتم العاشر للاتحاد العربي للمكتبات والمعلومات المكتبة الالكترونية والنشر الالكتروني وخدمات المعلومات. المعهد الأعلى للتوثيق، جامعة منوبة والاتحاد العربي للمكتبات

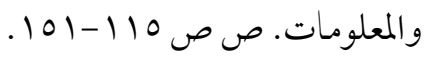

اع. الورفلن، طارق؛ ورمضان، محمد بن. (rا •r). النفاذ الحر وإتاحة الإنتاج العلمي: واقع

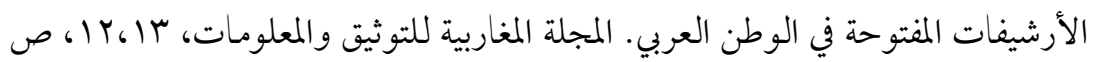

$$
\text { ص }
$$




\section{References}

- Abdel Aal, Najla Abdul Tawab Issa. (2016). Design a research map of the Department of Education assets, Faculty of Education, Ben-Suef University in light of research priorities. Future of Arab Education, 23 (101), pp. 293 425. (IN Arabic)

- Abdul Aziz, Karimman Baknam Sidqi. (March, 2015). Effect of international publication on the ranking of universities in international classifications: Cairo University as a model. Cybrarians Journal, 37. Retrieved from: http://journal.cybrarians.info/index.php?option=com_content $\&$ view=article \&id=688:kareman\&catid=273:studies\&Itemid=93 (IN Arabic)

- Abu Aliain, Hashem Mohammed; Khalil, Maher Hasab Elnabe; and Jizawi, Nasser Khamis. (2017). The effectiveness of the iThenticate program in preventing plagiarism and improving the quality of the outputs of scientific research among postgraduate students at Benha University. Second Scientific Conference of Libraries and Information: International Scientific Publishing: Reality, Challenges and Solutions. Benha: Faculty of Arts, University of Benha. Pp. 1-17. (IN Arabic)

- Adams, J. (2003). Assessing Faculty Performance for Merit: An Academic Accomplishment Index. Journalism \& Mass Communication Educator, 58(3), pp. 240-250.

- Ahmad, Ahmed Faraj. (2017). Platforms of social networks and their role in promoting the movement of scientific publishing: a comparative analytical study. Twenty-Eighth Conference of the Arab Union of Libraries and Information: Social Networks and Influences in Information Institutions in the Arab World, 27-29 November 2017. Cairo: Arab Union for Libraries and Information. Pp. 1-19. (IN Arabic)

- $\quad$ Ahmed, Najm el-deen Nasr; Abdullah, Mohammed Abdullah Mohammed; and el-Hanafi, Rasha Mustafa el-Sayed. (2018). A proposal to develop the field of pedagogy in the light of some international models. Educational and 
psychological studies: Journal of Faculty of Education Zagazig, (100), pp. 177-232. (IN Arabic)

- Al-Arabi, Ahmed Abadah; Abdul Ghaffar, Alaa Mohammed. (2017). Standard Specification for International Publishing. Researches of the Second Scientific Conference of Libraries and Information: International Scientific Publishing Reality, challenges and solutions. Egypt: Faculty of Arts, Banha University. Pp. 1-55. (IN Arabic)

- Al-Arishi, Jibril bin Hassan Arishi. (2004). Electronic Publishing. Informatics, 2, pp. 21-25. (IN Arabic)

- Al-Banna, Ahmed Abdullah Al-Saghir. (2014). The team was considered as an input to guarantee the quality of educational research in Egyptian education colleges. 8th Arab Scientific Conference (5th International Conference) Educational Scientific Production in the Arab Environment Value and Impact. Sohag: Faculty of Education, Sohag University. Pp. 235-288. (IN Arabic)

- Alghanim, Mona bin Abdullah bin Ali. (2018). Obstacles of academic electronic publishing: descriptive study. King Fahd National Library Journal, 24 (1), pp. 5-39. (IN Arabic)

- Al-Housh, Abu Bukr Mahmoud. (2001). Transition from traditional publishing to electronic publishing. The 10th Conference of the Arab Union for Libraries and Information The electronic library, electronic publishing and information services. Higher Institute of Documentation, Manouba University and the Arab Union of Libraries and Information. Pp. 115-151. (IN Arabic)

- $\quad$ Al-Hussawi, Najla bint Hamza Mohammed. (2016). Educational Theses in the foundations of education in Saudi universities, a future vision for a research map. Journal of Education for Educational, Psychological and Social Research, Faculty of Education, Al-Azhar University, 2 (170), pp. 578-631. (IN Arabic) 
- Al-Khalifa, Hind bint Sulaiman. (1431 H). Review of local and international experiences to involve BS students in scientific publishing and international conferences. Seminar on Higher Education for the girl dimensions and aspirations, 18-20 Muharram 1431 H. Medina: University of Tiba. Pp. 591-602. (IN Arabic)

- Al-Mabriz, Abdullah bin Ibrahim. (October, 2012). Academic publication in the sources of free access and its role in enriching Arabic content on the Internet. Journal of the Arab Federation for Libraries and Information (AFLI), 11, pp 120-142. (IN Arabic)

- Al-Nashar, El-Sayed El-Sayed. (2000). Electronic Publishing, Alexandria: Dar Al-thaqafa Al-Elmyah. (IN Arabic)

- Al-Obeidi, Saif Qudamah Younis; Al-Dabbagh, Raed Abdel Qader Hamid. (2013). The role of free access to information in the promotion of the scientific research movement: A survey of the views of a sample of faculty members at the University of Mosul. TANMIAT AL-RAFIDAIN, 35, pp. 121-143. (IN Arabic)

- Al-Razzi, Mohammed bin Abi Bakr bin Abdul Qader. (2005). Mokhtar AlSahah, I 9. Amman: Dar Ammar. (IN Arabic)

- Al-Sarhani, Wafaa Fahid. (2012). Electronic publishing and scientific research. Arab Studies in Education and Psychology, 22 (1), pp. 203-246. (IN Arabic)

- Al-Shazli, Nehal Ahmed Abdul Qadir; Mahjoub, Hasna Mahmoud Ahmed. (2017). Scientific publication at the Universities of Menoufia and King Saud and its impact on the global ranking of the two universities. International Journal of Library and Information Sciences, 4 (2), pp. 398408. (IN Arabic)

- Al-Werfali, Tareq; and Ramadan, Mohammed bin. (2013). Free Access and Availability of Scientific Production: The Reality of Open Archives in the Arab World. Maghreb Journal of Documentation and Information, 12,13, pp. 47-62. (IN Arabic) 
- $\quad$ Al-Zahrani, Jamaan bin Abdul Qader. (2016). E-Publication at Umm Al-Qura University: Obstacles and Solutions. Journal of Libraries and Information, 16, pp. 125-141. (IN Arabic)

- Ammar, Eman Hamdi Mohamed. (2012). Open Access to Information: A New Formula for Disseminating Scientific Research. The Eleventh Scientific Conference entitled The Crisis of Values in Educational Institutions. Fayoum: Faculty of Education, Fayoum University. Pp. 229-309. (IN Arabic)

- $\quad$ Anis, Ibrahim; Montaser, Abdel Halim; el-Sawalhi, Attia; Ahmed, Mohammed Khalaf Allah. (2004). AlMoajam Alwaseet. 4. Cairo: Shorouk International Library. (IN Arabic)

- Azab, Mohamed Ali Alyouh. (2013). Suggested research map of the Department of Educational Assets. Educational and psychological studies: Journal of Faculty of Education in Zagazig, 81, pp. 61-89. (IN Arabic)

- Dougherty, W. C. (2009). Print on Demand: What Librarians Should Know. The Journal of Academic Librarianship, 35(2), pp. 184-186.

- $\quad$ El Sherbini, Ghada Hamza; and Mohamed, Inas El Shafei. (2014). Obstacles to scientific publishing in educational sciences from the point of view of faculty members in Saudi universities. Journal of the Faculty of Education, Tanta University, (53), pp. 41-76. (IN Arabic)

- $\quad$ El-Dahshan, Gamal Ali. (2014). Features a proposed vision to promote Arab educational research. 8th Arab Scientific Conference (5th International Conference) Educational Scientific Production in the Arab Environment Value and Impact 26-27 April 2014. Sohag: Faculty of Education, Sohag University. Pp. 43-72. (IN Arabic)

- $\quad$ El-Dahshan, Gamal Ali. (2018). Towards an Arab Influence Factor for Quality and Evaluation of Journals and Scientific Research Published in Arabic: Necessities and Requirements. International Journal of Research in Educational Sciences, 1 (1), pp. 61-107. (IN Arabic) 
- $\quad$ Escaros, Philip. (2016). Anglo-American Research on the Origins of Education in the Near Future. The 23rd Annual Scientific Conference of the Egyptian Association for Comparative Education and Educational Administration "Education and Progress in North American Countries". Cairo: Egyptian Association for Comparative Education and Educational Management. Pp. 377-391. (IN Arabic)

- Ghanaim, Mahanna Mohamed Ibrahim. (2014). Educational Scientific Production in the Arab Environment: Reality and Hope. The 8th Arab Scientific Conference (The Fifth International) Educational Scientific Production in the Arab Environment, Value and Impact, 26-27 April 2014. Sohag: Faculty of Education, Sohag University. Pp. 101-142. (IN Arabic)

- Hafez, Diaa el-deen Abdel Wahid. (January, 2017). International scientific publication in phony journals on the Internet: a descriptive statistical study. Journal of the Arab Federation of Libraries and Information (AFLI), (18), pp. 133-163. (IN Arabic)

- $\quad$ Hasan, Mohammed Siddiq Mohammed; and Al-Kawari, Aisha Jassim. (2003). Electronic publishing in the balance. Journal of Education, 32 (144), pp. 60-76. (IN Arabic)

- Khalifa, Adel Mohammed Ahmed. (2018). Transition to electronic publishing: realistic solutions. Journal of Libraries and Information, (19), pp. 147-167. (IN Arabic)

- Kloe, Sabah Mohammed. (2018). Network Gate Research and its role in managing the inflation of scientific publishing and communication between researchers: Members of the faculty at the University of Sultan Qaboos model. The 24th Annual Conference of the Association of Specialized Libraries Gulf Arab Branch: The huge data and investment prospects: the path towards knowledge integration. Muscat: Association of Specialized Libraries, Gulf Arab Branch. Pp. 1-10. (IN Arabic)

- $\quad$ Laban, Hind Ali; and Al-Debian, Mudi Ibrahim. (2010). The reality of the free access movement in the information institutions belonging to the 
governmental and Ahlia universities in Riyadh city. Information Studies, 9, pp. 113-141. (IN Arabic)

- McNally, E. (2017). Webinars: Learning at Your Fingertips. Delta Kappa Gamma Bulletin, 84(2), pp. 50-52.

- $\quad$ Melhem, Essam Tawfiq. (2015). Obstacles of electronic scientific publishing from the viewpoint of faculty members at Naif Arab University for Security Sciences. Arab International Journal of Informatics, 7 (3), pp. 114. (IN Arabic)

- Mohammed, Aziza Ibrahim; Abdelhakem, Eman Mohamed; Salama, Amira; Mustafa, Hemmat; and Suleiman, Rehab. (2017). Scientific publishing and its role in promoting scientific and university research. Arab Studies in Education and Psychology, a special issue for research papers of the First International Conference of the Center for Developing the Capacity of Faculty Members and Leaders at Banha University, pp. 279-282. (IN Arabic)

- Mustafa, Gamal Mustafa Mohammed. (2011). Obstacles of academic epublishing from the point of view of faculty members in Arab universities. Arab Web Content Conference: Challenges and Aspirations. Imam Muhammad bin Saud Islamic University, pp. 21-65. (IN Arabic)

- $\quad$ Mustafa, Gamal Mustafa Mohammed. (2013). Research competencies in social sciences in the digital age. Journal of the Message of the Arabian Gulf, 130, pp. 139-180. (IN Arabic)

- Mustafa, Gamal Mustafa Mohammed. (2016). Factors Affecting Scientific Publishing in e-publishing among Arab University Faculty Members from their Point of View. Educational Journal, 30 (119 Part II), pp. 275-310. (IN Arabic)

- $\quad$ Puuska, H.-M. (2014). Scholarly Publishing Patterns in Finland A comparison of disciplinary groups. PhD, School of Information Sciences, University Of Tampere, School of Information Sciences. Finland: School of Information Sciences, University Of Tampere. 
- $\quad$ Radwan, Amal Salah Mahmoud. (2017). International scientific publication for researchers in Egyptian research centers and institutes. Second Scientific Conference of Libraries and Information: International Scientific Publishing "Reality Challenges and Solutions". Benha: Faculty of Arts, Benha University. Pp. 1-34. (IN Arabic)

- $\quad$ Rathore, S., Sharma, P. K., Loia, V., Jeong, Y.-S., \& Park, J. H. (2017). Social network security: Issues, challenges, threats, and solutions. Information Sciences, 421, pp. 43-69.

- Salager-Meyer, F. (2008). Scientific publishing in developing countries: Challenges for the future. Journal of English for Academic Purposes, 7, pp. 121-132.

- Shaheen, Sherif Kamel. (December, 2011). Random information on the web (web). Cybrarians Journal, 27. Retrieved from: http://www.journal.cybrarians.org/index.php?option=com_content\&view= article\&id=601:2011-12-01-22-02-06\&catid=251:2011-11 -28-21-18-27\& Itemid $=87 .($ IN Arabic)

- Sulaiman, Mohammed Al Hassan; Yahya, Maawiya Al Faki and Al Nour, Al Taher Ibrahim. (2017). Trends of Arab Researchers towards Scientific Publishing in Arabic in the Sources of Free Access: A Survey Study at King Faisal University. Journal of the Arab Center for Research and Studies in Library and Information Sciences, 4 (8), pp. 188-220. (IN Arabic)

- Yana, W., \& Zhangb, Y. (2018). Research universities on the ResearchGate social networking site: An examination of institutional differences, research activity level, and social networks formed. Journal of Informetrics, 2, pp. 385-400. 